\title{
Improving MJO simulation by enhancing the interaction between boundary layer convergence and lower tropospheric heating
}

\author{
Young-Min Yang ${ }^{1,2} \cdot$ Bin Wang ${ }^{1,2}$
}

Received: 30 January 2018 / Accepted: 12 August 2018 / Published online: 20 August 2018

(c) The Author(s) 2018

\begin{abstract}
It has been a great challenge for global weather and climate models to simulate realistic Madden-Julian Oscillation (MJO) while keeping global energy and water balance unaffected. This work demonstrates that, in the Nanjing University of Information Science and Technology Earth System Model, enhanced boundary layer (BL) convergence feedback to the lower tropospheric heating in both the modified Tidtke (TDK) and relaxed Arakawa-Schubert (RAS) convective schemes have significantly improved the quality of MJO simulation in terms of both the eastward propagation and three-dimensional dynamic and thermodynamic structures. The modifications to the TDK and RAS schemes include (a) a BL depth-dependent convective inhibition, and (b) a bottom-heavy diffusivity in the shallow convection scheme. To understand how these modifications improved the MJO simulation, we applied dynamics-oriented diagnostics to reveal the critical role of the interaction between the lower-tropospheric heating and the BL convergence. The modified schemes enhance the lower-tropospheric diabatic heating to the east of the MJO convective center, which leads to increased Kelvin wave easterly winds. The strengthened MJO easterly winds reinforce the BL moisture convergence to the east of the MJO center and therefore result in increased upward transports of moisture and heat from the BL to the free atmosphere, which further moisten and destabilize the lower troposphere and thereby increase the lower-tropospheric heating. The positive feedback between the BL convergence and lower tropospheric heating improves MJO eddy available potential energy generation to the east of major convection and promotes MJO eastward propagation. The results indicate that correct simulation of the heating induced by shallow and/ or congestus clouds and its interaction with BL dynamics is critical for realistic simulation of the MJO as suggested by the trio-interaction theory.
\end{abstract}

Keywords MJO $\cdot$ MJO simulation $\cdot$ MJO dynamics $\cdot$ Boundary layer convergence feedback $\cdot$ Shallow and congestus clouds

\section{Introduction}

The Madden Julian Oscillation (MJO) is characterized by slowly eastward-propagating precipitation and circulation anomalies that are largely confined between $15^{\circ} \mathrm{S}$ and $15^{\circ} \mathrm{N}$, which result in $20-70$ days oscillations in the tropics. Successful simulation and prediction of the MJO are

Bin Wang

wangbin@hawaii.edu

1 Earth System Modeling Center, Key Laboratory of Meteorological Disaster of Ministry of Education, Nanjing University of Information Science and Technology, Nanjing, China

2 Department of Atmospheric Sciences and International Pacific Research Center, University of Hawaii, Honolulu, HI 96822, USA vital for subseasonal prediction that bridges weather and seasonal mean climate prediction (Waliser et al. 2006) and for forecast of tropical cyclones, extreme weather events, and monsoon and ENSO (Vitart 2014; Vitart and Molteni 2010; Shi et al. 2009). Despite that simulation and prediction of the MJO with global climate model (GCM) have achieved considerable progress, many current global weather and climate models still fail to simulate the MJO eastward propagation (e.g., Jiang et al. 2015). It remains a great challenge to realistically simulate the MJO in global weather and climate models while keeping global energy and water balance unaffected.

Based on observations and model results, a number of processes and mechanisms have been suggested to explain MJO propagation. The first is the coupled Rossby-Kelvin wave (CRK) theory (Wang 1988; Wang and Rui 1990; Wang and Li 1994), which attributes the MJO propagation 
to the convective interaction with the Rossby-Kelvin wave and boundary layer (BL) convergence. The BL convergence-induced heating precedes the major MJO convection, resulting in the MJO coupled Kelvin-Rossby wave structure, eastward propagation and selection of the preferred unstable planetary scale. The spatial phase relationship between the BL convergence (sea level low pressure) and major convection is supported by observations (e.g., Madden and Julian 1972; Hendon and Salby 1994; Maloney and Hartmann 1998; Hsu and Li 2012) and is consistent with the observed westward and upward tilt of anomalous precipitation heating in the lower troposphere (Lin et al. 2004). It is also consistent with the "stepwise" transition from shallow/congestus to deep convection (Johnson et al. 1999, 2015; Kikuchi and Takayabu 2004; Katsumata et al. 2009). Hsu and Li (2012) found that the $\mathrm{BL}$ convergence-induced moistening to the east of MJO convection is a primary cause for the MJO eastward propagation, while the BL convergence is related to the heating-induced free atmosphere wave dynamics. The second mechanism is stratiform cloud-wave interaction (Mapes 2000; Khouider and Majda 2006; Kuang 2008; Fu and Wang 2009; Seo and Wang 2010; Holloway et al. 2013). Fu and Wang (2009) and Seo and Wang (2010) showed that the latent heating released in stratiform clouds produces MJO eddy available potential energy (EAPE), which allows direct interaction between heating and largescale circulation and sustains the MJO. The third is the cloud-radiation interaction (Lee et al. 2001; Raymond 2001; Lin and Mapes 2004; Bony and Emanuel 2005; Andersen and Kuang 2012). In observational studies, Lin and Mapes (2004) discovered that convective heating anomaly is associated with a radiative heating anomaly which has the same sign and a considerable magnitude. The fourth is the moisture-convection feedback (Woolnough et al. 2001; Grabowski and Moncrieff 2004; Sobel and Maloney 2012, 2013; Benedict et al. 2014), and the moist static energy transport (Maloney 2009; Maloney et al. 2010; Andersen and Kuang 2012; Hsu and Li 2012; Kim et al. 2014; Pritchard and Bretherton 2014; Wang et al. 2018). Maloney et al. (2010) emphasized the role of meridional moisture advection and wind-induced latent heat flux to the intraseasonal moist static energy on MJO simulation. The eastward propagation is due to advection of anomalous moisture by perturbed wind and mean westerly flow.

The essential MJO physics is rooted in the trio-interaction among diabatic heating, moisture, and dynamics (equatorial waves and boundary layer) (Wang et al. 2016). The recently proposed trio-interaction theory is a combination of CRK dynamic mode and moisture mode theories. Using a general trio-interaction model with the simplified Betts-Miller cumulus parameterization scheme (Wang and Chen 2017), it was shown that the $\mathrm{BL}$ dynamics is a primary driver for the eastward propagation of the MJO system, and the moisture feedback and wave feedback can slow down the eastward propagation. Wang and Lee (2017) revealed that the eastward propagation in GCMs is led by the lower tropospheric heating and EAPE generation to the east of MJO precipitation center, suggesting that MJO simulation in GCMs may critically depend on the diabatic heating released in shallow and congestus clouds.

Recently, the third version of the Nanjing University of Information Science and Technology (NUIST) Earth System Model (NESM3.0 for short hereafter) has been developed to provide a numerical modeling platform for the crossdisciplinary Earth system studies, to project future Earth's climate and environment changes and to simulate past climate changes, as well to conduct subseasonal-to-seasonal prediction. An earlier version of the NESM3.0 simulates reasonable climatology, global monsoon and teleconnection, but the MJO simulation is poor. Signals of the eastward propagation are very weak and the MJO convection tends to be standing over the Indian Ocean (IO) (Fig. 1b).

Previous GCM simulations have reported that it is important to control the onset of convection for better MJO simulation (Lee et al. 2001; Lin et al. 2008; Kim et al. 2011). The Tokioka constraint (Tokioka 1988) turns off the convection where the BL is relatively shallow. The Tokioka constraint improves the MJO simulation significantly in the atmospheric GCM (Lee et al. 2001) with the relaxed Arakawa-Schubert (AS) convective scheme. In the AS type convective scheme, multiple updrafts (generally different cloud tops) are assumed at a given grid box and the entrainment rates of each updraft are not calculated by buoyancy or vertical velocity of the updraft, rather it is adjusted to fit in those arbitrary cloud tops. Therefore, the deep convection with very small entrainment rate can occur when air is dry and the buoyancy of the updraft is relatively small. Introducing the Tokioka constraint can suppress this type of dry deep clouds when the BL is relatively shallow. However, the Tokioka constraint may cause large changes in the mean states of precipitation and associated circulations (Kim et al. 2011), particularly in coupled climate models. The Tokioka constraint also alters the global energy balance as well as the global climate variability including the ENSO (Li et al. 2018). Moreover, the Tokioka constraint may over-suppress deep or middle clouds in the convective scheme with a single updraft since a fixed criterion for all cloud types was used. In this study, the modified Tokioka constraint will be used to improve the MJO simulation without degrading other aspects of the global climate simulation under the singlecloud convective scheme.

In addition, it has been emphasized that the shallow convection is critical for improving MJO (Benedict and Randall 2007; Thayer-Calder and Randall 2009; Tseng et al. 2015; 
(a) OBS

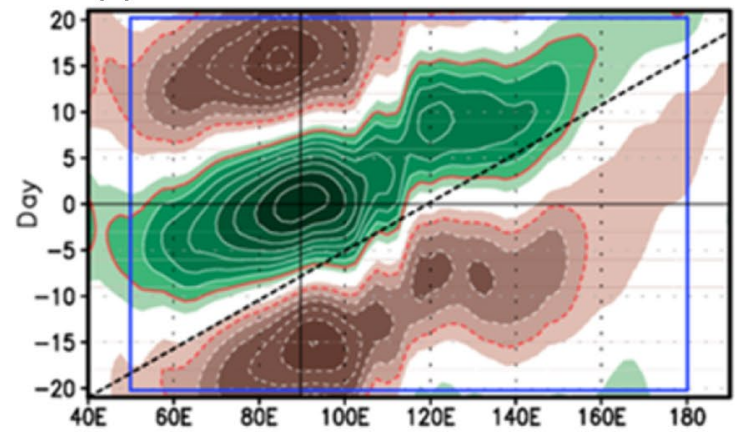

(b) CTL TDK

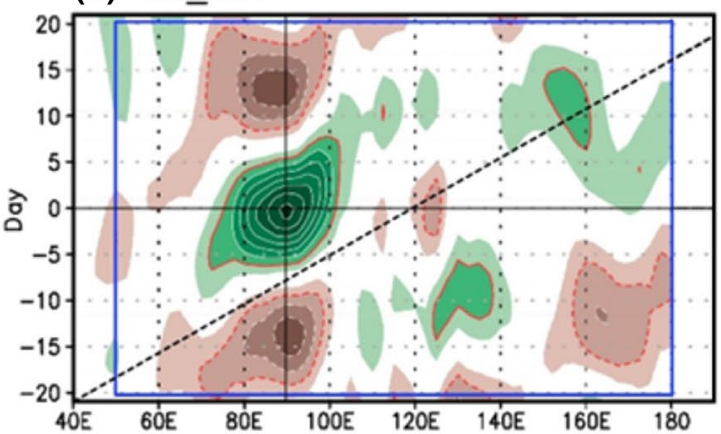

(d) $\mathrm{SHC}$

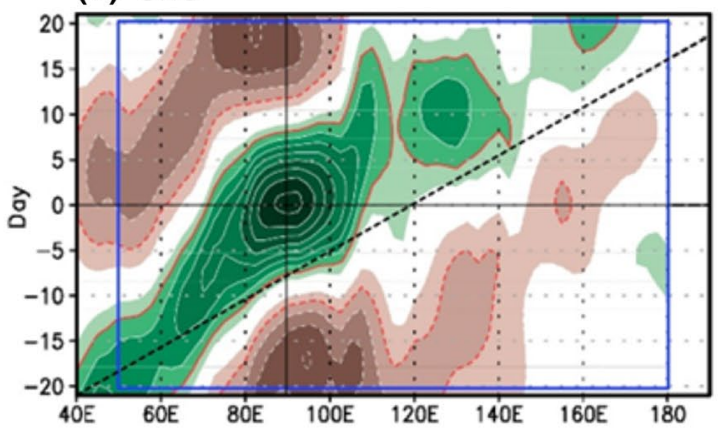

(f) $C T L-R A S$

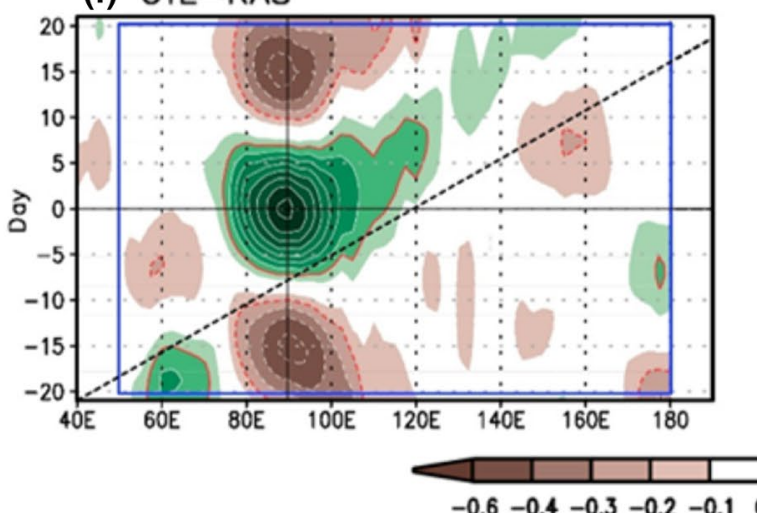

(c) $\mathrm{INH}$

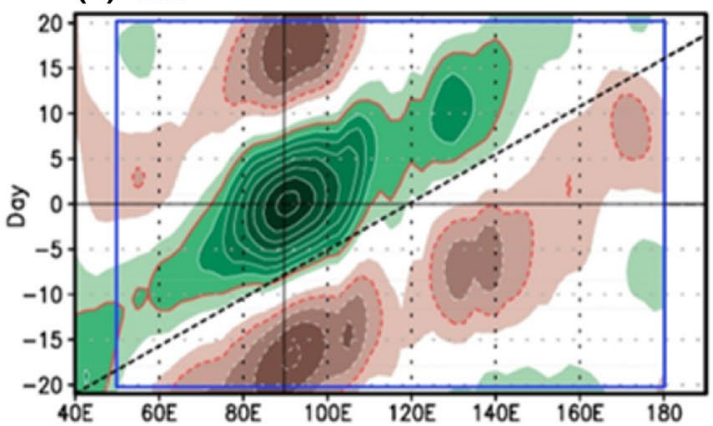

(e) $M-T D K$

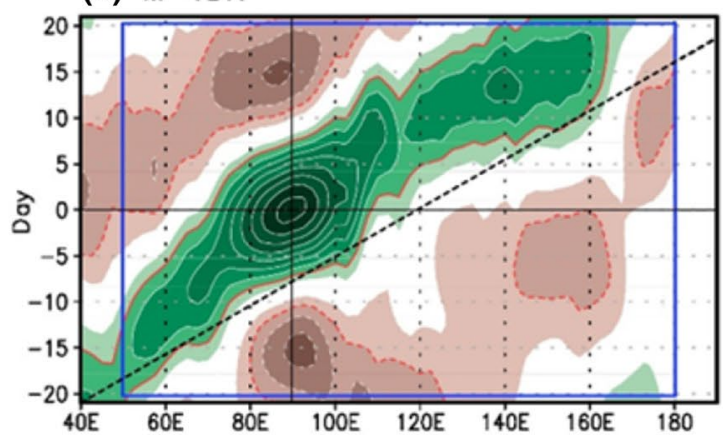

(g) M-RAS

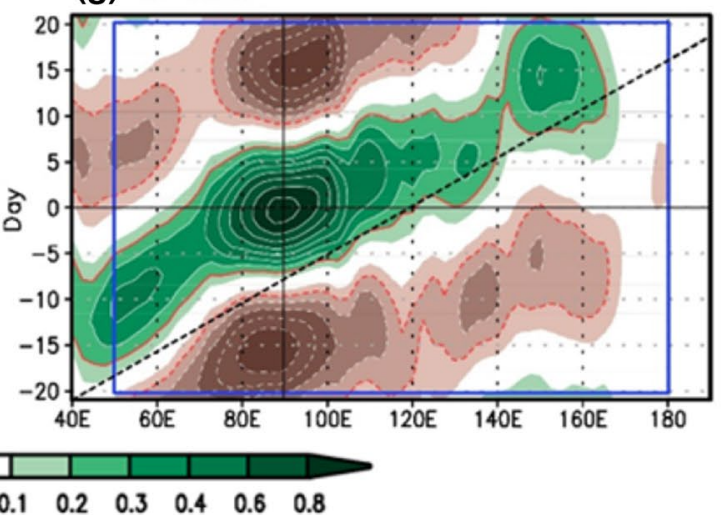

Fig. 1 Propagation of MJO precipitation as depicted by the leadlag correlation of 20-70 days filtered precipitation averaged over $10^{\circ} \mathrm{S}-10^{\circ} \mathrm{N}$ with reference to the precipitation at the MJO convective center over the equatorial Indian Ocean $\left(10^{\circ} \mathrm{S}-10^{\circ} \mathrm{N}, 80^{\circ}-100^{\circ} \mathrm{E}\right)$ during boreal winter (NDJFMA), which is derived from a observation and model simulations in the experiments of b CTL-TDK, $\mathbf{c}$ INH, d SHC, e M-TDK, f CTL-RAS and $\mathbf{g}$ M-RAS. The red contour repre- sents the correlation coefficient of \pm 0.2 . The black dotted line indicates an eastward propagation speed of $5 \mathrm{~m} \mathrm{~s}^{-1}$. Black dotted lines indicate eastward propagation speed of $5 \mathrm{~m} \mathrm{~s}^{-1}$. The black rectangular line represents the area used for PCC. Horizontal black line is lag of 0 and vertical black line is longitude of $90^{\circ} \mathrm{E}$. The abbreviations of the numerical experiments are listed in Table 1 
Cai et al. 2013). The shallow convection increases upward transport of moisture and heat from the BL to lower troposphere during a developing MJO event, which contributes to pre-moistening and pre-conditioning for deep convection development. In the original NESM3.0 without modified parameterizations, shallow convection mainly occur near the top of the $\mathrm{BL}$ and the lower troposphere, indicating that the vertical mixing between the lower troposphere and the top of the BL is insufficient. This study proposes a modified shallow convective scheme that enhances vertical mixing between the lower troposphere and the BL top by increasing coefficients of vertical diffusion.

This study describes how the MJO simulation is improved through modification of cumulus parameterization schemes and explains why the modified parameterizations improve the MJO simulation. Section 2 introduces the NESM3.0 and presents data and diagnostic methods. Section 3 exhibits the modified parameterization schemes that are able to enhance shallow or congestus clouds to the east of MJO major convection. In Sect. 4 we explain how the modified parameterizations improve MJO simulation based on the dynamicsoriented diagnostics. The last section presents a summary.

\section{The model, data and diagnostic methods}

\subsection{The NESM3.0 model}

The newly developed NESM3.0 couples the Nucleus for European Modelling of the Ocean (NEMO) v3.4 ocean model, version 4.1 of the Los Alamos sea ice model (CICE), the ECHAM v6.3 atmospheric model and the associated Jena Scheme for Atmosphere Biosphere Coupling in Hamburg (JSBACH) land surface model through version 3.0 of the Ocean-Atmosphere-Sea-Ice-Soil Model Coupling Toolkit (OASIS3-MCT_3.0). For details of the NESM3.0, please refer to Cao et al. (2018), since only a brief introduction is presented here. The ECHAM v6.3 and JSBACH model are originally developed at the Max Planck Institute (Stevens et al. 2013; Giorgetta et al. 2013). Both the short wave and long wave radiation schemes are taken from the rapid radiation transfer model for general circulation models (RRTM-G) scheme (Iacono et al. 2008). The turbulent transport uses the turbulent kinetic energy scheme, and the surface fluxes are calculated with the Monin-Obukhov similarity theory. The convective parameterization is based on the mass-flux framework developed by Tiedtke (1989) and further modified by Nordeng (1994) (TDK, hereafter). The stratiform cloud scheme contains prognostic equations for the vapor, liquid, and ice phase, a cloud microphysical scheme, and a diagnostic cloud cover scheme. The subgrid scale orographic parameterization scheme (Lott 1999) is incorporated to represent momentum transports arising from subgrid orography. The JSBASH land surface model simulates the fluxes of energy, momentum, moisture, and tracer gases between the land surface and the atmosphere (Raddatz et al. 2007). The ocean component model of the NESM3.0 is Ocean PArallelise (OPA), which is the ocean part of NEMO v3.4. The OPA model uses the isotropic Mercator projection south of $20^{\circ} \mathrm{N}$ and the stretched grid north of $20^{\circ} \mathrm{N}$ with two poles in Canada and Siberia. The sea ice model in the NESM3.0 is CICE v4.1, which is originally developed at the Los Almos National Laboratory. The model solves dynamic and thermodynamic equations for five categories of ice thickness, and the ice thermodynamics are calculated at five ice layers corresponding to each thickness category. The OASIS3-MCT_3.0 (Valcke et al. 2013) coupler is a fully parallelized tool to synchronize, interpolate and exchange the coupling fields among the atmospheric, oceanic and sea ice component models.

The resolution of the atmospheric model is T63 horizontally and 47 levels vertically with $0.01 \mathrm{hPa}$ as the model top. The land surface model has the same horizontal resolution as the atmospheric model. The ocean model has a resolution of $1^{\circ}$ latitude and longitude grid with the meridional resolution being refined to $1 / 3^{\circ}$ over the equatorial region, and it has 46 vertical layers with the first 15 layers at the top $100 \mathrm{~m}$. The sea ice model resolution is about $1^{\circ}$ latitude by longitude with four sea ice layers and one snow layer on the top of the ice surface.

\subsection{The data and diagnostic methods}

The European Center for Medium-Range Weather Forecast Reanalysis (ERA) Interim data (Dee et al. 2011) are used to calculate circulation anomalies. The precipitation data are derived from the Global Precipitation Climatology Project (GPCP) daily data (Adler et al. 2003). The period of data covers 18 years from 1997 to 2014. A 20-70 days band-pass filter is used to identify the MJO signal during the winter season (November 1st-April 30th). Three diagnostic methods were used in the study. The first is the basic MJO diagnostic suggested by CLIVAR MJOWG (Waliser et al. 2009). The climatological precipitation, SST and surface winds were examined and the total (or filtered) variance and space-time spectrum of precipitation were analyzed. The second is the dynamics-oriented metrics for the MJO described in Wang et al. (2018), which help to evaluate whether a model produces eastward propagating MJO for the right reasons. The diagnostics include (1) the horizontal structure of boundary layer moisture convergence (BLMC) that leads the propagation of MJO precipitation by about 5 days; (2) the horizontal structure of $850 \mathrm{hPa}$ zonal wind and its equatorial asymmetry (Kelvin wave easterly vs. Rossby wave westerly intensity), which result from the interaction between wave dynamics and convective heating; (3) 
the equatorial vertical-longitudinal structure of equivalent potential temperature (EPT), which reflects the pre-moistening and pre-destabilization processes; (4) the equatorial vertical-longitudinal distribution of diabatic heating, which reflects the multi-cloud structure of the $\mathrm{MJO}$; (5) the upperlevel divergence; and (6) generation of the MJO EAPE, which reflects the amplification and propagation of the MJO. Generally speaking, models with better simulation of threedimensional dynamic and thermodynamic structures of the MJO reproduce better eastward propagations. To measure performance of the simulated MJO, simple Hovmöller diagram is utilized to display the lead-lag correlation map of anomalous precipitation with respect to the precipitation anomaly over the equatorial Indian Ocean (EIO, $10^{\circ} \mathrm{S}-10^{\circ} \mathrm{N}$, $\left.80^{\circ}-100^{\circ} \mathrm{E}\right)$. The EIO precipitation anomaly is used as a reference for constructing correlation or regression maps in this study, because the MJO convective variability center with the most prominent 40-50 days oscillation is located in the EIO and the organized eastward propagation of the MJO starts from the EIO most frequently (Wang and Rui 1990; Waliser 2006; Kikuchi et al. 2012). All MJO structures shown in Figs. 6, 7, 8, 9, 10, 11, 12, 13, 14 and 15 (except Fig. 13) are constructed with regressed 20-70 days filtered daily data. To facilitate comparison, strengths of the regressed fields are scaled to a fixed $3 \mathrm{~mm}^{-1 a y}{ }^{-1}$ precipitation rate at the EIO. The third is the lagged composites of EPT, diabatic heating and EAPE by Del Genio and Chen (2015) to show premoistening, pre-destabilization in the EPT field and promotion of EAPE generation ahead of the MJO major convection.

\section{Modification of the cumulus parameterization schemes}

The convective scheme used in this study is the modified Tiedtke scheme proposed by Nordeng (1994), which is the default setting in the ECHAM6.3 (Peters et al. 2017 and; Möbis and Stevens 2012) (TDK, hereafter). This scheme includes shallow, deep and midlevel convection, but only one type of convection is allowed when convection takes place. The deep convection is allowed when large-scale moisture convergence equals to $110 \%$ of the BL moisture flux. The shallow convection can take place even when large-scale moisture convergence is smaller than the BL moisture flux or distance between cloud bottom and the level of neutral buoyancy is less than $200 \mathrm{hPa}$. The midlevel convection is activated if neither deep nor shallow convection can be triggered. This scheme calculates both updrafts and downdrafts. The updrafts involve organized entrainment and detrainment. The entrainment rate is calculated using buoyancy and vertical velocity of the updraft parcel, while the detrainment rate is a function of entrainment rate and the detrainment occurs from the level of maximum buoyancy to the cloud top. The downdraft appearing at the level of free sinking where the in-cloud air mixes with the environmental air is a function of cloud-base mass flux (e.g., 20\%). The convective APE is used for closure of deep convection scheme (Nordeng 1994) and the moisture convergence is employed for closure of shallow convection (Tiedtke 1989).

\subsection{The modified TDK scheme}

As shown in observations, the shallow cumulus and congestus clouds gradually develop into deep convective and stratiform clouds (Johnson et al. 1999, 2015; Kikuchi and Takayabu 2004; Katsumata et al. 2009; Virts and Wallace 2010; Del Genio and Chen 2015). It has been argued that one of the key processes for the eastward propagation of the $\mathrm{MJO}$ is the $\mathrm{BL}$ dynamics which interact with shallow or congestus clouds (e.g., Wang and Chen 2017; Wang et al. 2016). There is a positive feedback between the BL frictional convergence and shallow convective heating. The frictional convergence generates upward transports of moisture from the $\mathrm{BL}$ to the lower troposphere, thus producing shallow convective heating, which in turn enhances the BL moisture convergence. This implies that adequate simulation of shallow and/or congestus clouds and their interaction with the BL may be essential for MJO simulation in GCMs. Based on this hypothesis, two modifications have been implemented into the TDK scheme so as to improve the simulation of the shallow convective heating and their interaction with the BL moisture convergence. The main differences between the modified TDK scheme used in this study and the original TDK are (1) implementation of an inhibition function and (2) implementation of the shallow convective scheme with bottom-heavy diffusivity.

\section{The BL depth-dependent convective inhibition}

A convective inhibition is added to the TDK scheme. This inhibition is a modified Tokioka (1988) constraint. The original Tokioka constraint have been used in the convective scheme based on multiple updraft/downdraft (e.g. Arakawa-Schubert scheme) in the atmosphere model with prescribed SST (Lee et al. 2001; Lin et al. 2008). The entrainment rates of each updraft are not calculated by the buoyancy or vertical velocity of the updraft, rather it was adjusted to fit those arbitrary cloud tops. Therefore, deep convection with a very small entrainment rate can occurs when air is dry and the buoyancy of updraft is relatively small. The Tokioka constraint suppresses this dry deep cloud when the PBL is relatively shallow. In this study, the Tokioka constraint is implemented in the TDK scheme, which is based on a single updraft. It compares the entrainment 
rate estimated from the original TDK scheme with the minimum entrainment rate from Eq. (1). If the entrainment rate is smaller than the minimum entrainment rate, the convection will turn off. Initially, when we simply added the TOK in the TDK scheme, the deep cloud or middle cloud tend to be over-suppressed and the convective instability is excessively accumulated, particularly in the tropics, which has to be removed by large-scale clouds, inducing increased cloudiness. The increased cloudiness has a large impact on the model climatology and global energy balance, particularly in the coupled model. The model simulated SST with the original TOK is $2.5 \mathrm{~K}$ colder than in the model without the original TOK over tropics. The amount of global net short (long) wave radiation at the top of the atmosphere is reduced by 4.5 (4.7) $\mathrm{W} \mathrm{m}^{-2}$. In order to reduce these negative impacts of the TOK without degrading the MJO simulation, we used different criteria for the onset of each cloud type in the TOK. The criteria for deep and middle convection is more relaxed than that for the shallow convection, thus deep clouds can be more frequently generated when compared to the use of the original uniform criterion. The modified Tokioka constraint is defined as

$\varepsilon_{\min }=\frac{a_{i}}{\mathrm{~h}}$

where $\mathrm{h}$ refers to the BL depth. In the original Tokioka scheme, the parameter $a_{i}$ is taken as a constant and $i$ is the cloud type (deep, midlevel and shallow convection). In this study, the values of $a_{i}$ are taken as $0.02,0.015$ and 0.01 for the shallow, midlevel and deep convection, respectively. For example, $\varepsilon_{\min }$ for deep convection is $10^{-5} \mathrm{~m}^{-1}$ over the tropical ocean $(\mathrm{h}=1 \mathrm{~km})$, which is within the normal range of entrainment rate for deep convection. The modified Tokioka constraint prohibits immediate development of deep convection, allowing gradual transition from shallow to deep convection. After modifying the criteria, the changes of SST and global energy balance are much reduced $(0.5 \mathrm{~K}$ for SST and $2.3 \mathrm{~W} \mathrm{~m}^{-2}$ for radiation at the TOA), which is acceptable compared to most CMIP5 models. Therefore, the modified TDK used in this study can improve MJO simulation without degrading model's climatology and energy balance.

2. A bottom-heavy diffusivity in the shallow convection scheme

Previous results have emphasized the importance of shallow convective heating and moistening of the BL for MJO propagation. In the context of these findings, we elaborated how we modified the shallow convection in the TDK scheme. In the model simulation with the original TDK scheme, it is found that shallow convection mainly occurs near the top of the BL (900-1000 hPa) and/or lower troposphere $(600-700 \mathrm{hPa})$, indicating that the vertical mixing between the lower troposphere and the top of BL is insufficient. To overcome this deficiency, the diffusive processes in the shallow convection were added to the TDK scheme. This scheme is described by the following diffusive terms for large scale (grid mean) dry static energy $\mathrm{S}$ and specific humidity q (Tiedtke et al. 1988):

$\frac{\partial \overline{\mathrm{s}}}{\partial \mathrm{t}}=\frac{1}{\bar{\rho}} \frac{\partial}{\partial \mathrm{z}}\left\{\bar{\rho} \mathrm{K} \frac{\partial}{\partial \mathrm{z}}(\overline{\mathrm{s}}-\mathrm{L} \overline{\mathrm{l}})\right\}$

$\frac{\partial \overline{\mathrm{q}}}{\partial \mathrm{t}}=\frac{1}{\bar{\rho}} \frac{\partial}{\partial \mathrm{z}}\left\{\bar{\rho} \mathrm{K} \frac{\partial}{\partial \mathrm{z}}(\overline{\mathrm{q}}+\overline{\mathrm{l}})\right\}$

where $l$ denotes cloud liquid water content, $\rho$ the air density, $\mathrm{L}$ the latent heat, $\mathrm{t}$ time and $\mathrm{z}$ height. The coefficient $K$ is the eddy diffusivity, which is a prescribed function of height or pressure. Different from the previous shallow convective scheme, we used a modified vertical profile of diffusion coefficient in the shallow convection scheme (see Fig. 2). This new "bottom-heavy" profile allows a more vigorous heat and moisture mixing between the BL and lower troposphere.

\subsection{The modified RAS scheme}

In order to see whether the modified schemes work in other parameterization schemes, the relaxed Arakawa Schubert (RAS, Lee et al. 2001) scheme is implemented into the NESM3.0 model. The RAS scheme differs from the TDK scheme in several aspects: (a) the TDK scheme is based on single (bulk) plume, whereas the RAS scheme considers a hierarchy of clouds (cloud ensemble); (b) the TDK generates only one type of clouds among shallow, midlevel and deep clouds at one grid, but the RAS allows all type of clouds to develop; (c) the TDK calculates entrainment rate with the updraft buoyancy, while the entrainment rate in the RAS is computed by assuming that the buoyancy of updraft is zero at the cloud top, which is prescribed in the scheme. The aforementioned two modified schemes are also implemented into the RAS scheme.

As summarized in Table 1, four experiments are carried out by using the TDK scheme to examine the impacts of modified parameterizations: (1) the original TDK without modification (CTL-TDK), (2) the TDK with the convective inhibition function (INH), (3) the TDK with the modified shallow convection (SHC), and (4) the TDK with combined INH and SHC modifications (M-TDK). Two additional experiments are performed using the RAS scheme. One is CTL-RAS, in which the original RAS is used, while the other employs the modified RAS with combined INH and SHC and is referred to as M-RAS hereafter. Noted that the models have not been retuned for each change of the convective parameterizations. Only the parameterizations described in the Table 1 were changed. For all experiments, 
Table 1 Experiments with modified convective parameterization schemes in the NESM3.0

\begin{tabular}{lll}
\hline Exp. & Convective parameterization & Modified scheme \\
\hline CTL-TDK & Tiedtke scheme (Peters et al. 2017) & - \\
INH & Tiedtke scheme (Peters et al. 2017) & BL depth-dependent convective inhibition \\
SHC & Tiedtke scheme (Peters et al. 2017) & Bottom-heavy diffusivity in the shallow \\
& & convection scheme \\
M-TDK & Tiedtke scheme (Peters et al. 2017) & INH + SHC \\
CTL-SAS & Relaxed Arakawa-Schubert scheme (Lee et al. 2001) & - \\
M-SAS & Relaxed Arakawa-Schubert scheme (Lee et al. 2001) & INH +SHC \\
\hline
\end{tabular}

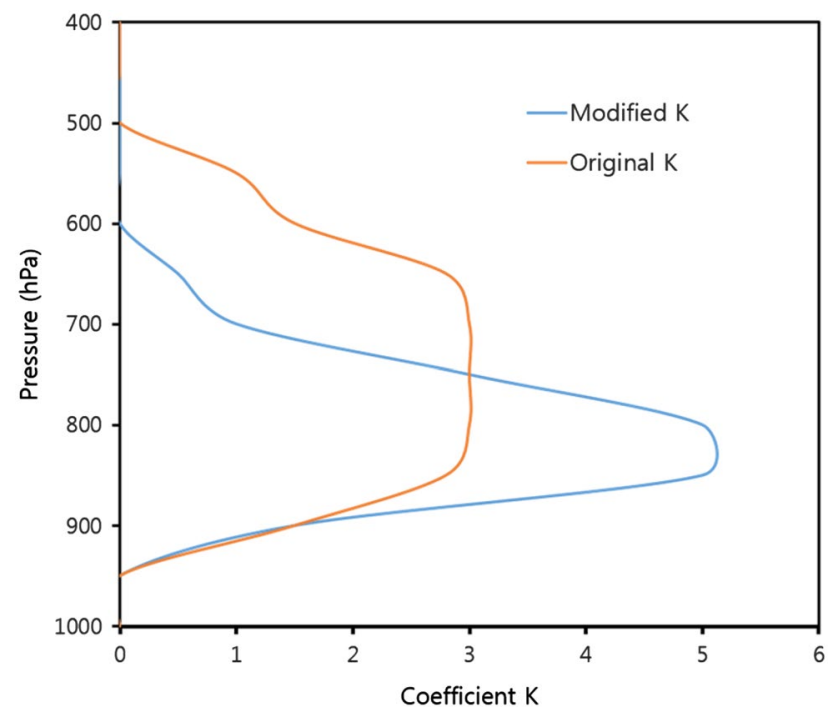

Fig. 2 Vertical profiles of eddy diffusion coefficient $\mathrm{K}$ used in the original Tokioka constraint (orange) and in this study (blue)

the model was integrated for 50 years using fixed 1990s external forcings (greenhouse gases, solar constant, aerosol concentration, ozone, etc.) based on the coupled model intercomparison project phase 6 (CMIP6) protocols and the last 20-year data were used for analysis. The initial condition for the 50-year integration was obtained from a historical run based on the CMIP6 protocols. The NESMs with the modified TDK and RAS schemes use the same parameter settings to facilitate comparison. It is worth noting that models with modified schemes simulate reasonable climatology, monsoons and teleconnections, which are all similar to those simulated in the CTL, suggesting that the modified schemes improve MJO simulation without degrading climatology and global energy and water balance.

\section{How the MJO propagation is improved}

\subsection{Improved MJO propagations with the modified cumulus schemes}

Figure 1a shows the observed propagation diagrams of MJO precipitation with reference to the MJO precipitation center at the EIO. Eastward propagation with a speed about $5 \mathrm{~m} \mathrm{~s}^{-1}$ is seen for both wet and dry events. In the CTL-TDK (Fig. 1b) and CTL-RAS (Fig. 1f), where the original TDK and RAS schemes are used in the NESM3.0, propagation of precipitation is hardly discernible; the MJO convection in the EIO tend to be standing. Similar features are found in the CTL simulations in the propagation diagram of precipitation with reference to the MJO precipitation center in the equatorial western Pacific (figures not shown). However, with the modified TDK schemes that utilize the INH, SHC, and in particular, M-TDK, the models simulate systematic eastward propagation of the MJO from the Indian Ocean to the western Pacific, indicating that the modified parameterizations improve the MJO simulation significantly. Comparison of the CTL-RAS and M-RAS confirms that the modified RAS scheme also improve MJO simulation considerably.

\subsection{Basic MJO diagnostics}

We have examined the differences in precipitation, SST and surface zonal wind between the modified parameterizations (INH, SHC and M-TDK) and the CTL (Fig. 3).

In the INH experiment, the mean SST is $0.5 \mathrm{~K}$ colder than that of the CTL in the western Pacific but no significant difference in the Indian Ocean (Fig. 3a shading). The INH tends to suppress deep convection where the BL is shallow, thus large-scale condensation increases, which induces colder SST by increasing cloudiness. This process is not effective in the Indian Ocean due to relatively low relative humidity. The precipitation is reduced due to colder SST over the western Pacific but slightly increased over the eastern Pacific (Fig. 3a contour). The change of precipitation reduces upward motion over the western Pacific and decreases sinking motion over the eastern Pacific, which 
(a) INH - CTL_TDK

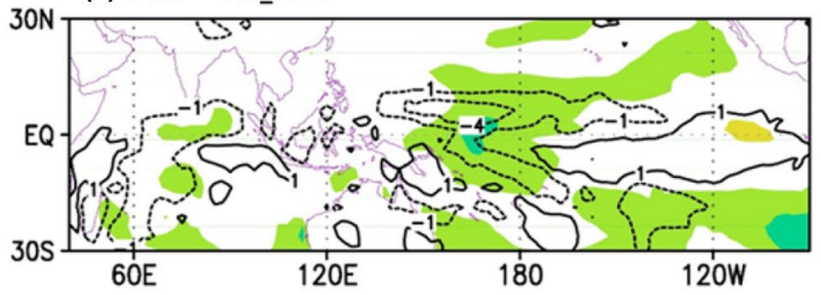

(b) SHC - CTL_TDK

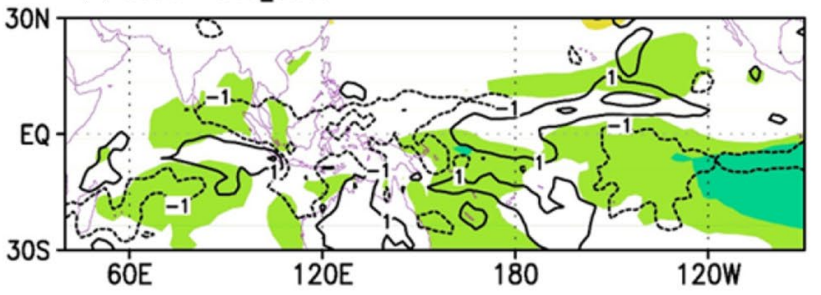

(c) M-TDK - CTL_TDK

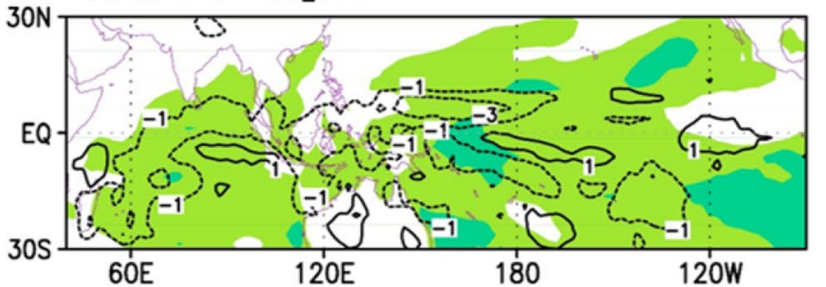

(d) INH - CTL_TDK

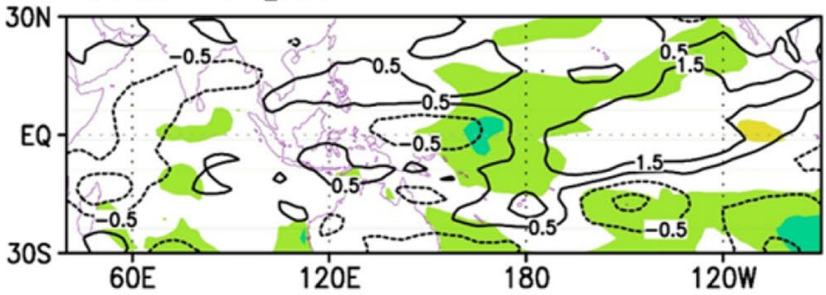

(e) SHC - CTL_TDK

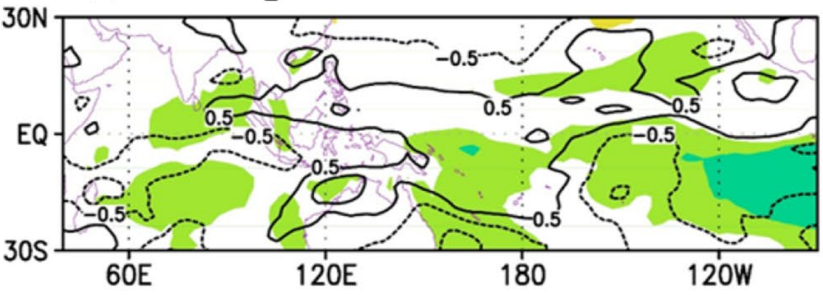

(f) M-TDK - CTL_TDK

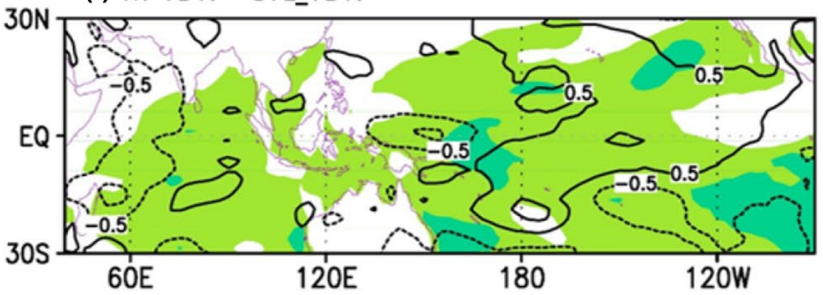

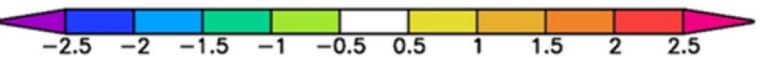

Fig. 3 Difference of November-April mean surface temperature (shading, K), precipitation (contour, a-c, mm day ${ }^{-1}$ ) and surface zonal wind (contour, $\mathbf{d}-\mathbf{f}, \mathrm{m} \mathrm{s}^{-1}$ ) between CTL and INH, SHC and M-TDK

weakens the Walker circulation and the associated easterly over the central-eastern Pacific (Fig. 3d contour). The moderate change of surface zonal winds over the Indian Ocean and western Pacific does not affect MJO appreciably. On the other hand, the decreased SST over the western Pacific may slightly prohibit occurrence of the MJO convection.

In the SHC, the SST is about $0.5 \mathrm{~K}$ colder over the Indian Ocean and western Pacific where MJO convection is active (Fig. 3b shading). The SHC increases shallow convection all over the tropics, particularly in the eastern Pacific, which reduces deep convection and thus total precipitation over the eastern Indian Ocean and western Pacific (Fig. 3b contour). The SHC produces anomalous westerly wind over the MC and western Pacific, which may contribute to improving MJO propagation (Fig. 3e contour).

The M-TDK reduces precipitation over the tropics, particularly the western Pacific due to colder SST (Fig. 3c). There is anomalous easterly wind in the western Pacific (Fig. 3f). The change of SST and surface wind by M-TDK may be unfavorable for improving MJO simulation.

Figure 4 shows the differences in the filtered and total precipitation variances between observation and model simulations. In observation, the maximum total variance occurs in the IO and western Pacific. The ratio of the filtered to total variance of precipitation is about $30-50 \%$ (figure not shown). The CTL captures observed horizontal patterns but overestimates the magnitudes of the variances over the IO and western Pacific warm pool region. On the other hand, the INH and SHC, as well as the M-TDK all simulate smaller total variance of precipitation than the CTL in the warm pool oceans due to the decreased mean SST in the coupled model, yielding reduced bias in the variance patterns. The deep convection suppressed by the INH and SHC increases shallow convection, which may contribute to the reduction of the total variance. The corresponding filtered variances also decrease compared to the CTL, thus the ratio of the filtered to total variance is not much affected. In addition, over the central Africa and South America, the CTL simulates weaker total variance than observation. The INH, SHC and M-TDK have similar biases there.

Figure 5 below shows the wavenumber-frequency spectrum of the precipitation derived from observations and models. The observation is obtained from GPCP daily data, which indicates a concentration of power at 30- to 90-day periods and zonal wave number $1-3$. The peak of periods 
(a) CTL_TDK - OBS

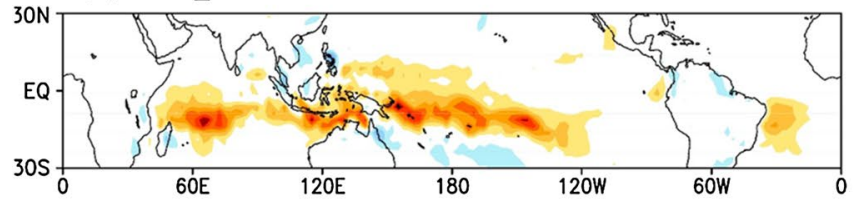

(b) INH - OBS

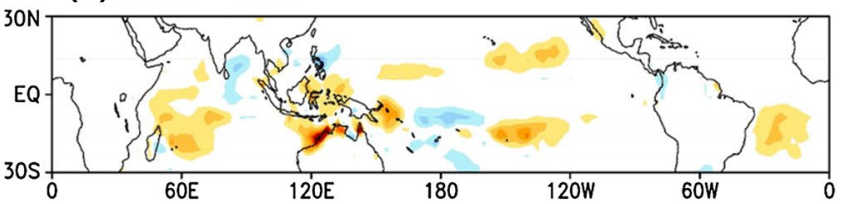

(c) $\mathrm{SHC}$ - OBS

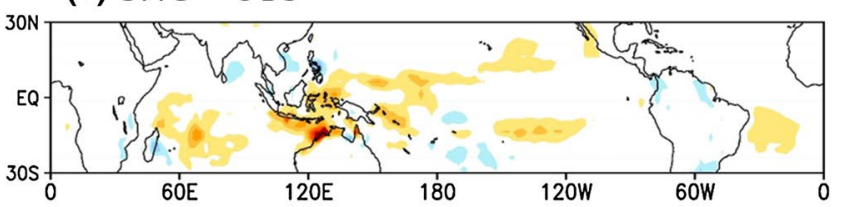

(d) M-TDK - OBS

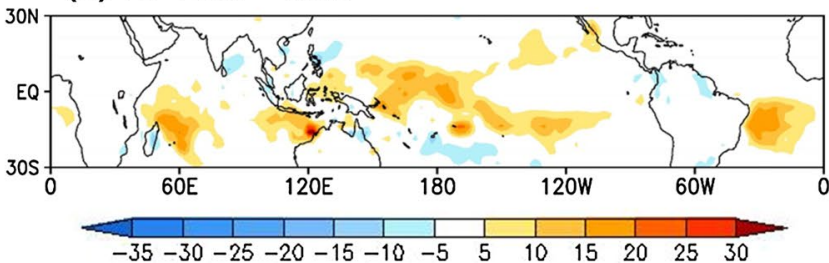

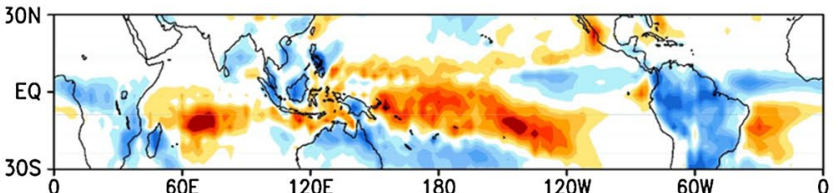
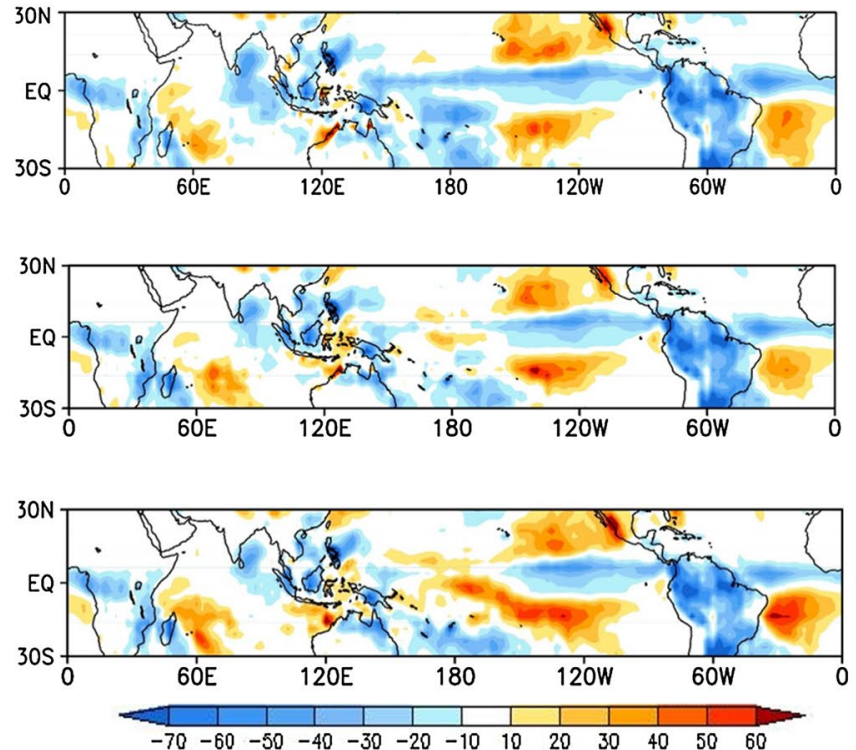

Fig. 4 Total (right panel) and 20-70 days filtered (left panel) variance of precipitation $\left(\mathrm{mm}^{-2} \mathrm{day}^{-2}\right)$ from observation and model simulations. Only statistically significant areas are shaded (95\% confidence level)

occurs at about 45 -day and zonal wave number one. The CTL simulates a peak power at 65-day period and zonal wave number five and a second peak at 200-day period, implying that the CTL does not capture the planetary horizontal scale and simulates a standing MJO. The INH and SHC have strong eastward powers at 55-day period and wave number 2-3, suggesting that they enhance the eastward propagation and can simulate planetary scale MJO events. The M-TDK has strong eastward power at 55-day period and wave number $1-3$, showing a better simulation of horizontal scales.

\subsection{Causes of improved MJO simulations with the modified TDK schemes}

To understand how the MJO simulation is improved, we diagnose the diabatic heating, circulation, and thermodynamic fields that are associated with the MJO. We start from diagnosis of the lower tropospheric $(700 \mathrm{hPa})$ diabatic heating field (Figs. 6, 7) and the circulation structure at $850 \mathrm{hPa}$ (Fig. 8) to see how the modified heating changes the circulation structure. Through examining the BL moisture convergence (Fig. 9) and vertical profile of the EPT (Fig. 10), we can then figure out how the changes in the circulation structure affect the BL convergence and how the modified BL convergence moistens and destabilizes the lower troposphere (Fig. 11) to the east of the MJO center, which in turn enhances the lower tropospheric heating. This positive feedback loop results in the generation of MJO EAPE and kinetic energy to the east of the MJO center (Fig. 12), thus improving the MJO eastward propagation.

Figure 6 shows the horizontal distribution of diabatic heating at $700 \mathrm{hPa}$ derived from observation and models. Because no observed diabatic heating field is available, we estimate it using the budget analysis proposed by Yanai et al. (1973) for both observation and model simulations. Here, the diabatic heating consists of the heating due to radiation, the release of latent heat by net condensation, and vertical convergence of the vertical eddy transport of sensible heat (it is called Q1 in Yanai et al. 1973). Note that in the model, the vertical profile of diabatic heating computed from the model is similar to that calculated using Yanai's method (not shown). In observation, positive diabatic heating occurs at the MJO convective center and extends eastward from $90^{\circ} \mathrm{E}$ to $\sim 150^{\circ} \mathrm{E}$. The CTL-TDK fails to simulate the eastward extension of diabatic heating along the equator (Fig. 6b). However, in the INH, SHC and M-TDK experiments, the modified schemes reproduce realistic the eastward extension 


\section{(a) OBS}

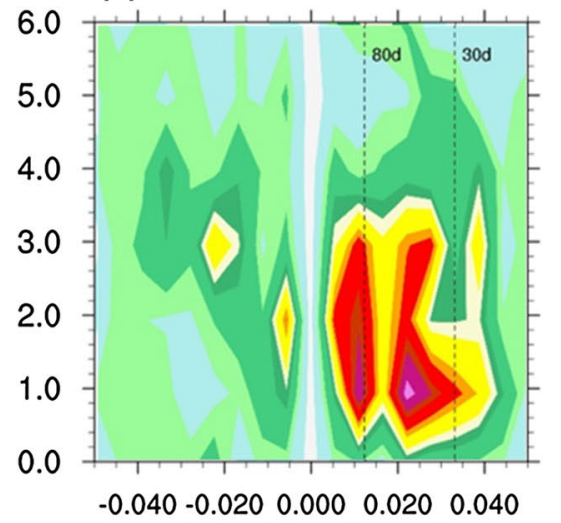

(b) CTL-TDK

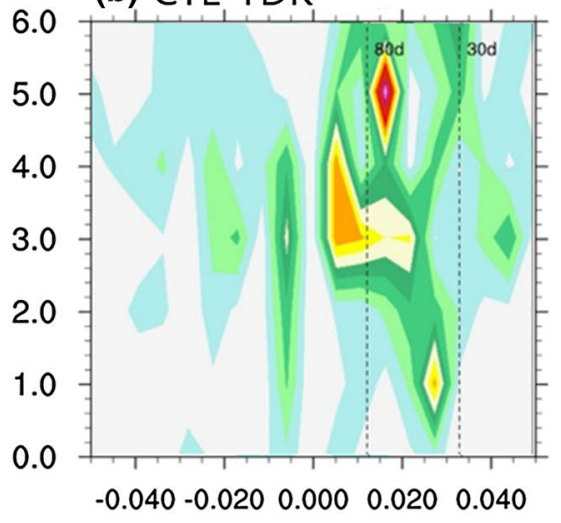

(d) $\mathrm{SHC}$

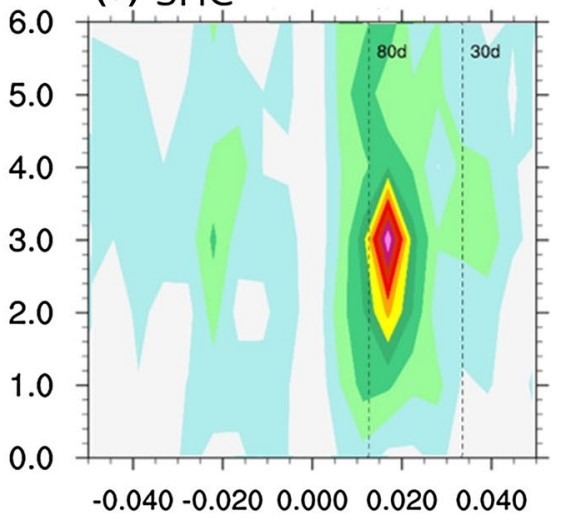

(c) INH

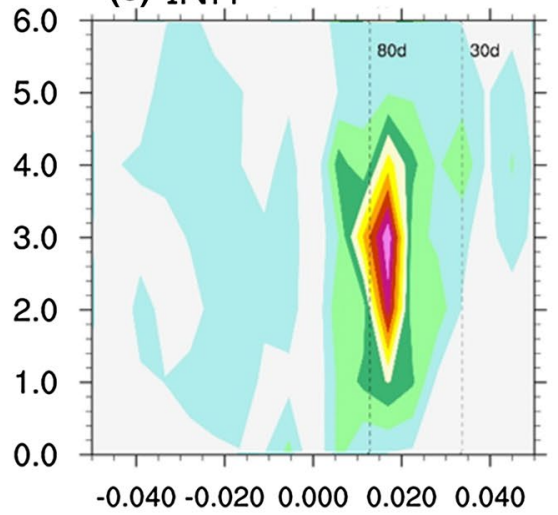

(e) M-TDK

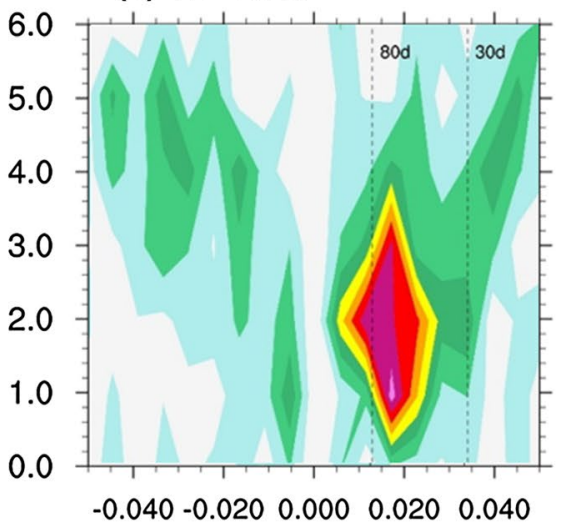

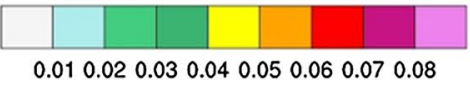

Fig. 5 November-April wavenumber-frequency spectrum of $10^{\circ} \mathrm{N}-10^{\circ} \mathrm{S}$-averaged a GPCP precipitation and $\mathbf{b}-\mathbf{e}$ models. Only the climatological seasonal cycle and time mean for each November-
April segment were removed before calculation of the spectra. Units for the spectrum are $\mathrm{mm}^{-2} \mathrm{day}^{-2}$

congestus clouds to deep convections (Johnson et al. 1999, 2015; Kikuchi and Takayabu 2004; Katsumata et al. 2009; Virts and Wallace 2010).

Figure 6 indicates that the enhanced lower tropospheric diabatic heating to the east of the MJO precipitation center has rectified the $\mathrm{MJO}$ circulation structure at the lower troposphere, such as at $850 \mathrm{hPa}$. Observation shows that the MJO exhibits a coupled Rossby-Kelvin wave structure in accord with the convective center in the Indian Ocean. The equatorial maximum westerly speed is slightly weaker than the maximum easterly speed (1:1.2) (Wang et al. 2018). The horizontal circulation pattern simulated in the CTL-TDK is different from that of the observed MJO: the zonal wind is not symmetric about the equator and the westerly to the west of the MJO center is stronger than the easterly to the east of the MJO center (Fig. 8b). The weak easterly in the CTL-TDK is consistent with the lack of lower tropospheric heating to the east of the MJO center (Fig. 6b). In contrast, the INH, SHC and especially 
(a) OBS

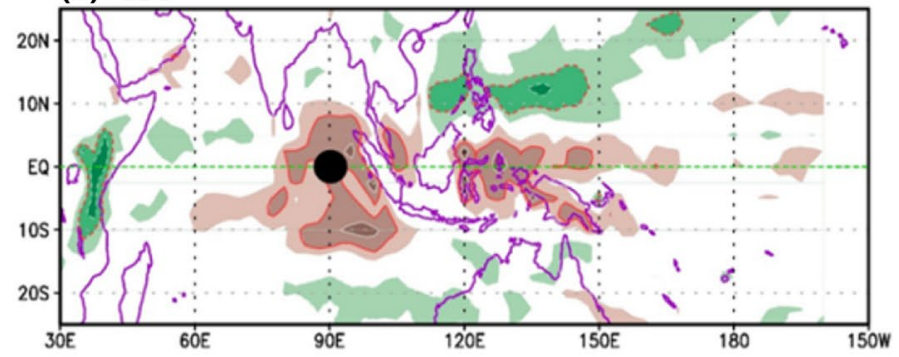

(b) $\mathrm{CTL}$ TDK

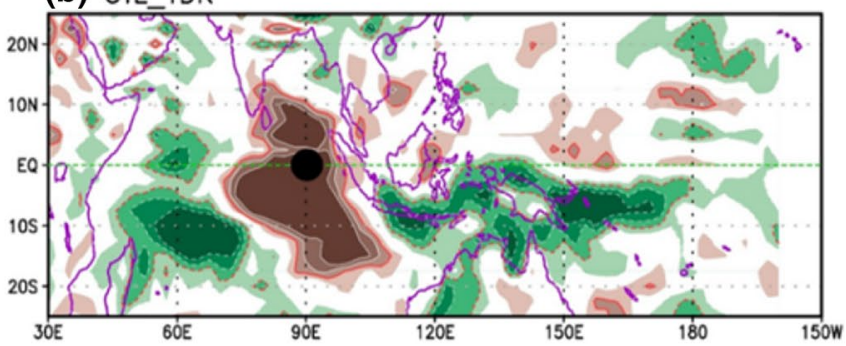

(d) $\mathrm{SHC}$

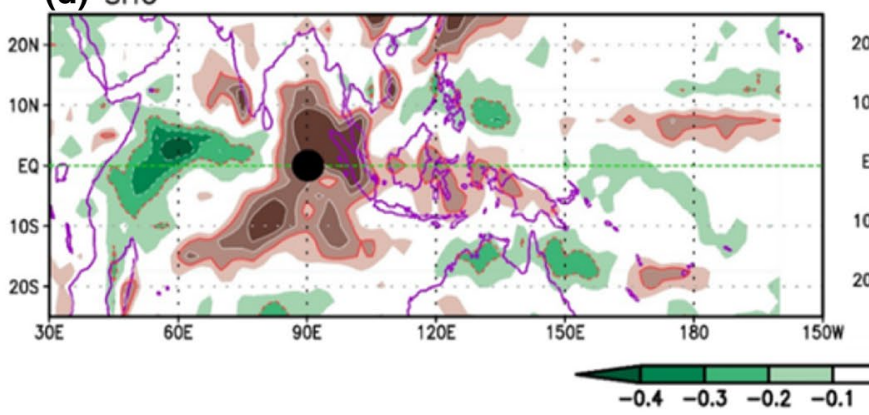

Fig. 6 Horizontal structure of diabatic heating at $700 \mathrm{hPa}$ in observation a and model simulations of $\mathbf{b}$ CTL-TDK, $\mathbf{c}$ INH, d SHC, and $\mathbf{e}$ M-TDK, depicted by the regressed 20-70 day filtered diabatic heating $\left(\mathrm{K} \mathrm{day}^{-1}\right)$ onto the 20-70 days filtered precipitation averaged over the

M-TDK experiments produce the circulation patterns that are much more similar to the observed one. Intensity of the maximum Kelvin wave easterly is comparable with observation and stronger than that of the maximum Rossby wave westerly. The enhanced Kelvin wave lowpressure and easterly are induced by the enhanced lower tropospheric heating to the east of the MJO center. The result here suggests that the modified parameterizations enhance the diabatic heating in the lower troposphere with increased shallow clouds, which improves the large-scale circulation structure of the MJO. The diabatic heating to the east of the MJO center deepens Kelvin wave lows and increases easterly winds, thereby reinforcing the BL moisture convergence.

Figure 9 shows the BL convergence of observation and model simulations at $925 \mathrm{hPa}$. In the observation, strong BLMC is located in the MJO precipitation center and extends eastward to the Maritime Continent and western (c) $1 \mathrm{NH}$

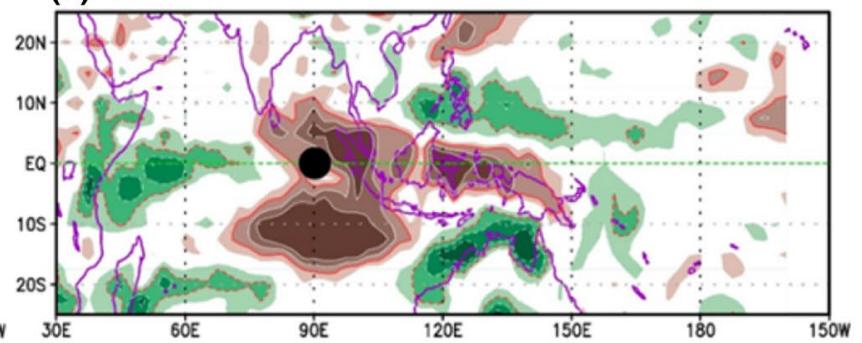

(e) $M-T D K$

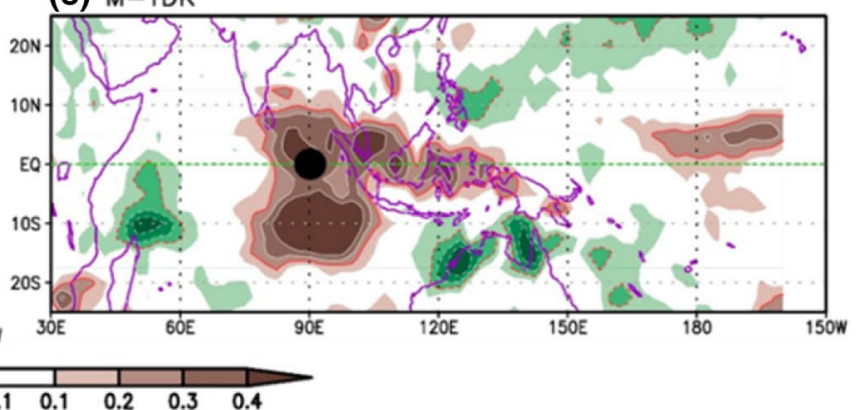

MJO precipitation center $\left(10^{\circ} \mathrm{S}-10^{\circ} \mathrm{N}, 80^{\circ}-100^{\circ} \mathrm{E}\right)$, which is symbolized by the black filled circle. The regression strengths are scaled to a fixed $3 \mathrm{~mm} \mathrm{day}^{-1}$ precipitation rate. The red contour represents the regression coefficient of \pm 0.2 . Green horizontal line is equator
Pacific. Magnitude of the BLMC to the east of the IO MJO center is comparable with that over the IO. The CTL-TDK simulates a strong BLMC over the MJO center but fails to capture the BLMC to the east of the MJO center: the BLMC there is negative at the equator. The pattern correlation coefficient (PCC) between the observed and CTLTDK simulation is only 0.35 in the domain $\left(80^{\circ} \mathrm{E}-150^{\circ} \mathrm{E}\right.$ and $\left.10^{\circ} \mathrm{S}-10^{\circ} \mathrm{N}\right)$. On the other hand, the INH, SHC and M-TDK experiments reproduce the observed extension of the BLMC to the east of the MJO center reasonably well. The horizontal pattern of the BLMC from the M-TKD resembles its observed counterpart with a corresponding PCC of 0.73. However, the model overproduces intensities of the BLMC, which is in accord with the overestimated diabatic heating intensities in the model (Figs. 6, 7). In both observation and model simulations, horizontal patterns of the BLMC are very similar to those of the corresponding lower tropospheric diabatic heating (Fig. 6b-e), 
Fig. 7 Equatorial zonal asymmetry in the diabatic heating ( $\mathrm{K}$ $\mathrm{day}^{-1}$, shading) and anomalous Walker cell $\left(\mathrm{m} \mathrm{s}^{-1}\right.$ for zonal wind and $0.01 \mathrm{~Pa} \mathrm{~s}^{-1}$ for the vertical velocity, vector) along the equator averaged between $5^{\circ} \mathrm{S}$ and $5^{\circ} \mathrm{N}$ in the observation $\mathbf{a}$ and model simulations of $\mathbf{b}$ CTL-TDK, c INH, d SHC, and e M-TDK. The structures in each panel are reconstructed using the same method as in Fig. 3. Green contour represents the regression coefficient of 0 . The blue vertical lines represent MJO precipitation center $\left(90^{\circ} \mathrm{E}\right)$. Only statistically significant areas of diabatic heating are shaded $(95 \%$ confidence level) (b) CTL_TDK

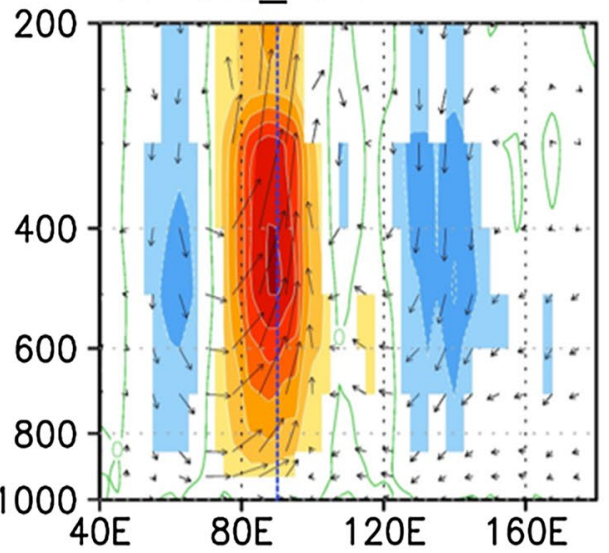

(d) $\mathrm{SHC}$

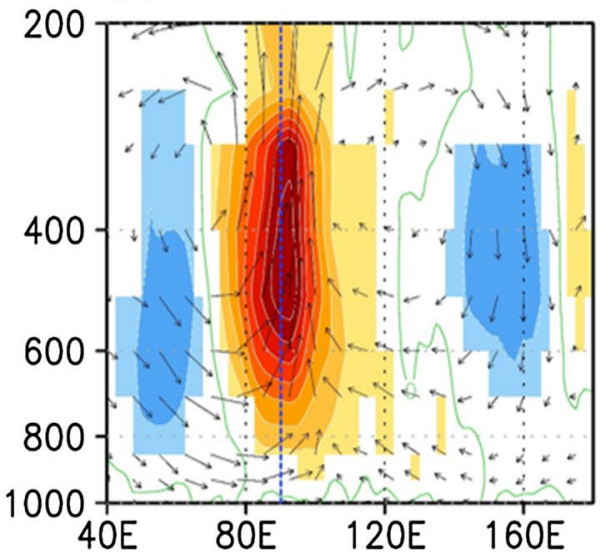

(a) OBS

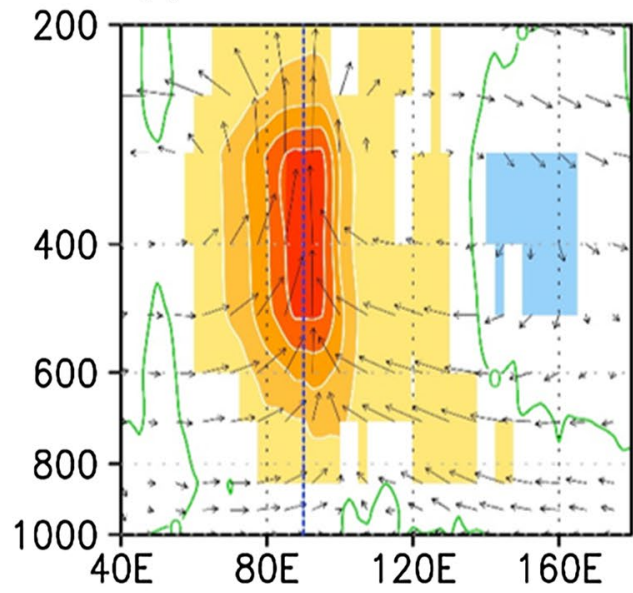

(c) $\mathrm{INH}$

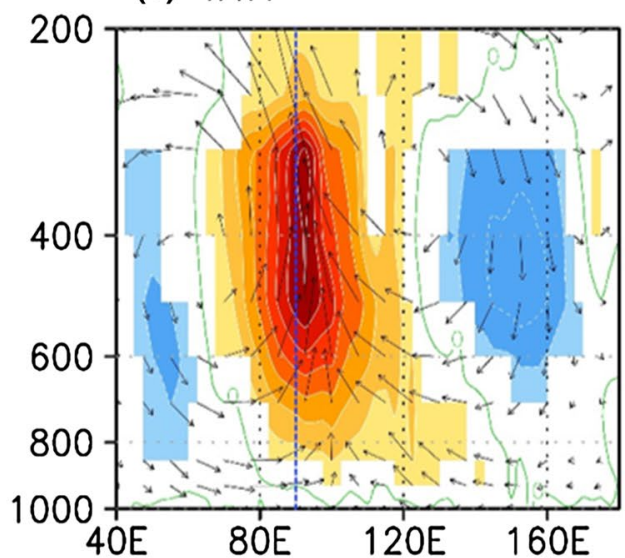

(e) $\mathrm{M}-\mathrm{TDK}$

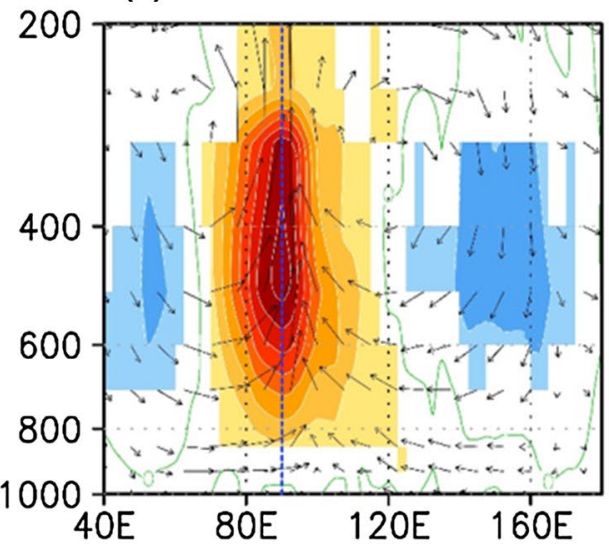

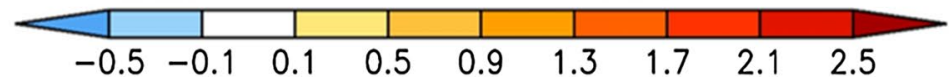

implying that the BLMC and lower-tropospheric heating are interactive.
The BLMC causes vertical motion, thus inducing vertical transport of heat and moisture from the BL to the lower 
(a) OBS

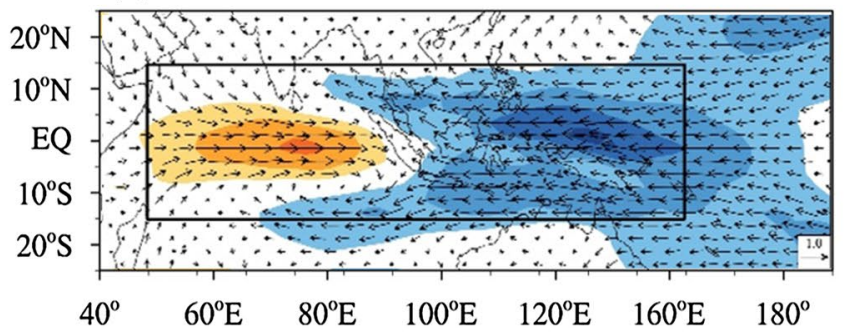

(b) CTL_TDK

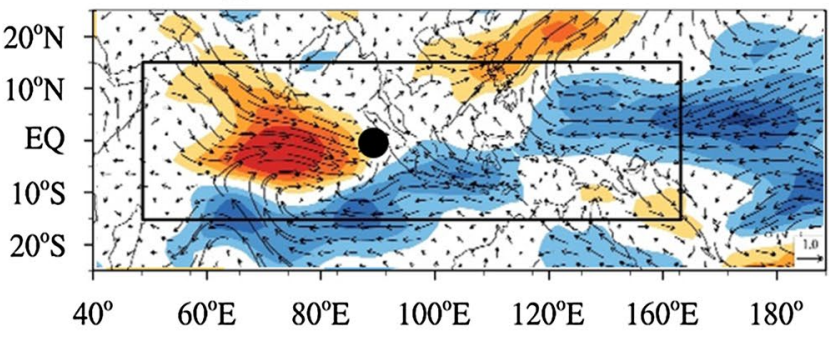

(c) $\mathrm{INH}$

(d) $\mathrm{SHC}$

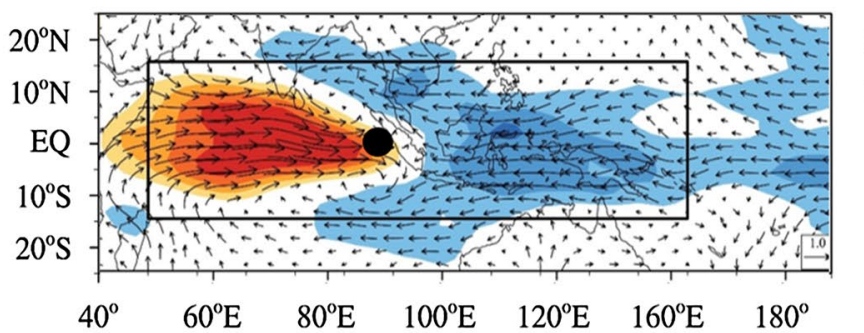

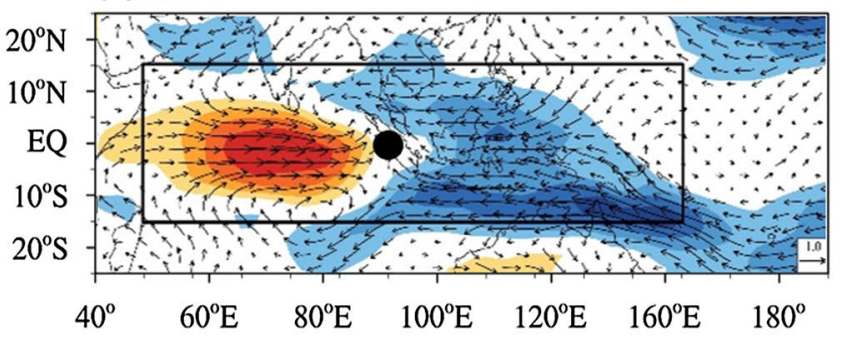

(e) M-TDK

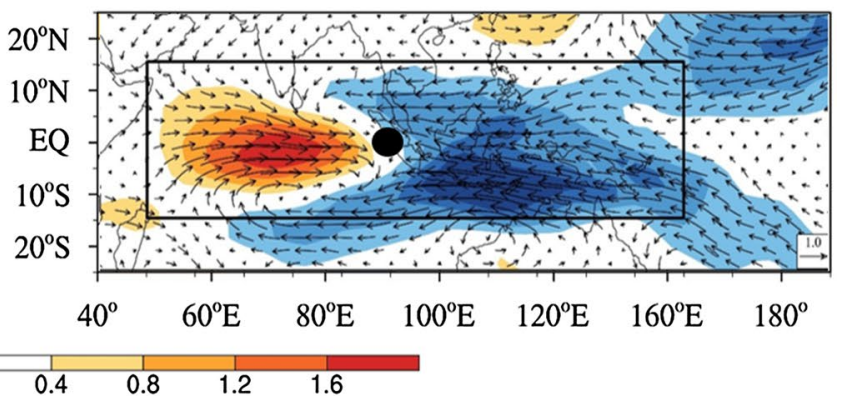

Fig. 8 The same as in Fig. 3 except for $850 \mathrm{hPa}$ winds $\left(\mathrm{m} \mathrm{s}^{-1}\right.$, vector) and $850 \mathrm{hPa}$ zonal wind speed (U850) (m s${ }^{-1}$, shading). The rectangular line represents the area used for PCC

troposphere. Previous studies have found that the moist layer is gradually deepened from the ground before the deep convective phase of the MJO (e.g., Bladé and Hartmann 1993; Johnson et al. 1999; Kemball-Cook and Weare 2001; Tian et al. 2006). In the tropical lower troposphere, the temperature anomaly is small, thus the EPT change primarily reflects moisture variation. To better depict the moistening and destabilization processes, we examine the EPT anomalies, which also represent the moist static energy anomalies and the moist thermodynamic structure of the MJO.

Figure 10 presents the observed and simulated vertical profiles of the EPT. Note that the observed EPT has a maximum near $500 \mathrm{hPa}$ around $90^{\circ} \mathrm{E}$, where the MJO precipitation center is located. An evident eastward extension of the EPT anomaly in the lower troposphere is seen in the observation, suggesting that the lower tropospheric moistening occurs ahead of the MJO center. All of the MJOs simulated in the INH, SHC and M-TDK have a maximum at $500 \mathrm{hPa}$ in the MJO precipitation center and exhibit a forward and downward extension of the maximum EPT, suggesting that higher EPT in the lower troposphere and BL occurs in advance of the MJO convective center. However, the CTLTDK simulates weaker EPT than observation and fails to capture the extension of EPT in the lower troposphere, indicating that there is no gradual moistening in the lower troposphere. The M-TDK replicates the observed structure of EPT in the lower troposphere reasonably well with a PCC of 0.80 between the observation and simulation. The magnitude of EPT to the east of the MJO center is similar to the observed counterpart, implying that inclusion of the M-TDK improves the thermodynamic structure of the MJO significantly.

As a result of pre-moistening, the convective instability is increased to the east of the MJO center. This is shown in Fig. 11, which compares the horizontal distribution of the convective instability index in observation and the CTL-TDK and M-TDK simulations. Following Wang et al. (2018), the convective instability index is defined as the EPT difference between 850 and $400 \mathrm{hPa}$. This index measures the pre-destabilizing condition ahead of the MJO deep convection. Observation shows negative convective 
(a) OBS

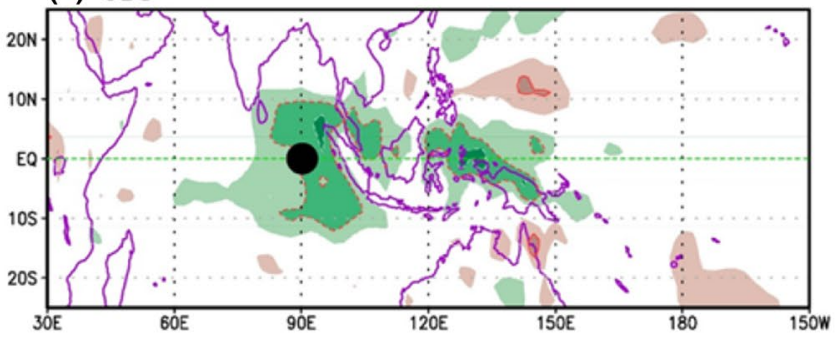

(b) CTL_TDK

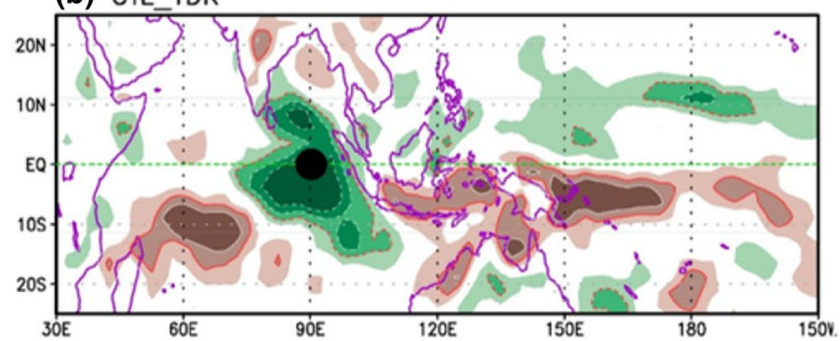

(d) $\mathrm{SHC}$

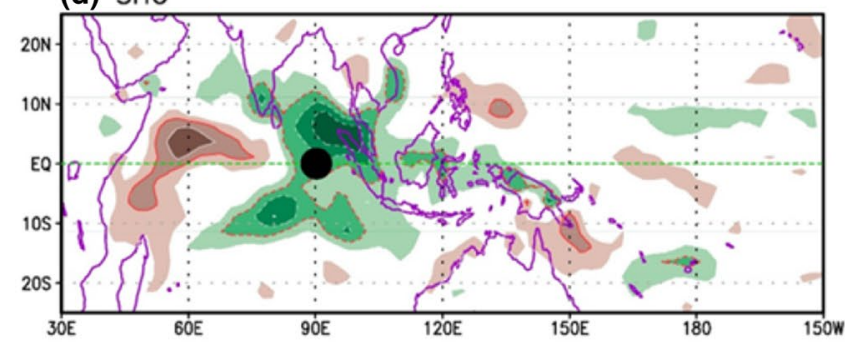

(c) $\mathrm{INH}$

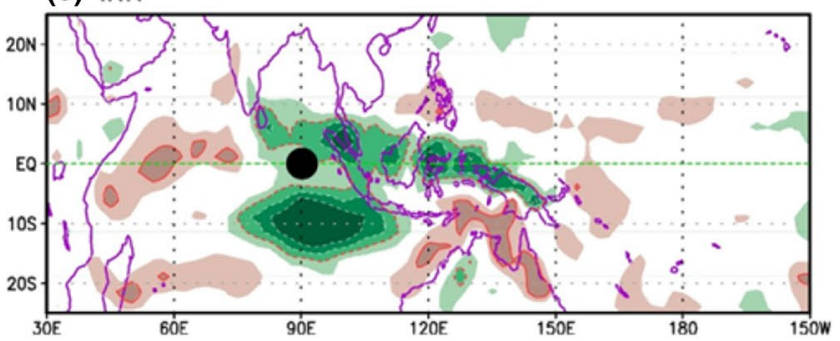

(e) $\mathrm{M}-\mathrm{TDK}$

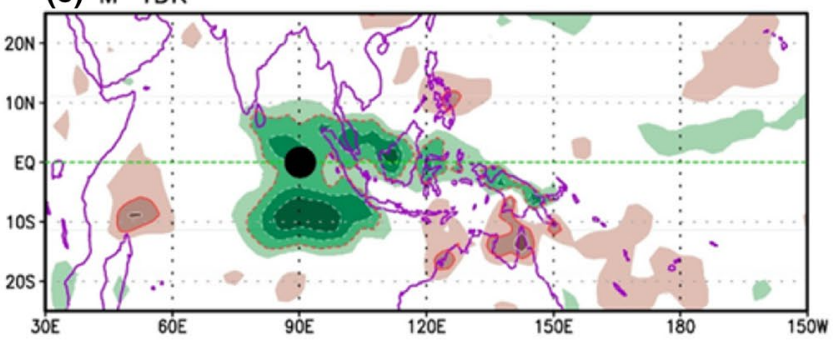

Fig. 9 The same as in Fig. 3 except for the moisture convergence at $925 \mathrm{hPa}\left(\mathrm{day}^{-1}\right)$. The red contour represents the regression coefficient of \pm 0.6 . Green horizontal line is equator

instability at the MJO precipitation center but positive convective instability to its east, indicating that deep convection is favored to the east of the existing deep convection (Fig. 11a). The positive instability extends to the warm pool regions (about $160^{\circ} \mathrm{E}$ ). The CTL-TDK does not produce the positive convective instability to the east of the MJO center, implying that the eastward propagation is not favored (Fig. 11b). The M-TDK captures the observed pattern of convective instability pretty well (Fig. 11e). In the model, the negative instability at the MJO center is stronger than in observation but the positive instability to the east of the MJO center is weaker than in observation, which is consistent with the EPT biases of the model.

Figure 12 shows the EAPE generation rate, which represents the energy source of MJO disturbance. The MJO EAPE is generated in the region where warmer air is heated or colder air is cooled. In observation, the maximum generation is located over the MJO precipitation center in the middle troposphere (400-500 $\mathrm{hPa}$ ), and coincides with the maximum diabatic heating (Fig. 7a). The observed EAPE is positive to the east of the MJO center, particularly in the lower troposphere. The zonal asymmetry in the EAPE generation with respect to the MJO precipitation center is consistent with that of the EPT and diabatic heating. Higher generation rate of the EAPE ahead of the MJO center leads to eastward propagation of the MJO due to conversion of the EAPE to eddy kinetic energy. In the temperature field, negative temperature anomaly was found in the lower troposphere over the IO center. Tseng et al. (2015) found in observation negative heating (Q2) below $6 \mathrm{~km}$ during the MJO mature and decaying phases. It implies that reevaporation of shallow convection or congestus cloud occurs there, with moistening in the lower troposphere. The moistening induces strong positive EPT but weak negative $\mathrm{T}$ anomalies. As shown in Fig. 9b, the CTL-TDK produces the negative EAPE to the east of the convective center in the lower troposphere, whereas the INH, SHC and M-TDK simulate positive energy generation there, suggesting that the modified parameterizations generate the EAPE that promotes eastward propagation. 


\section{(a) OBS}

(b) CTL_TDK

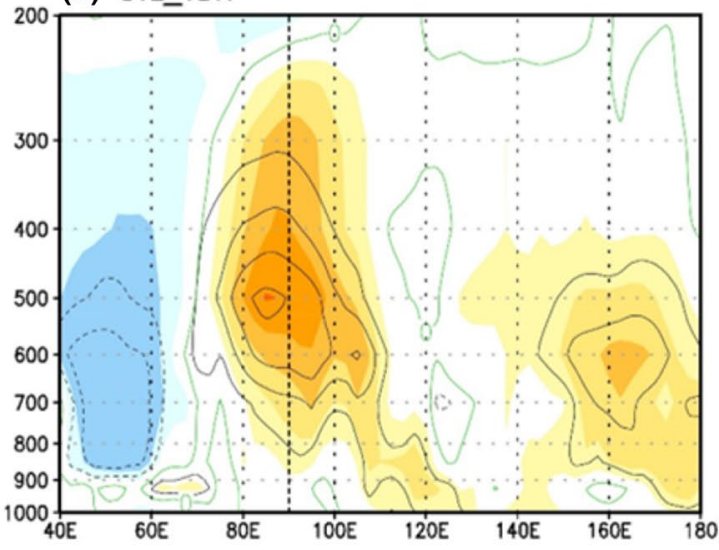

(d) $\mathrm{SHC}$

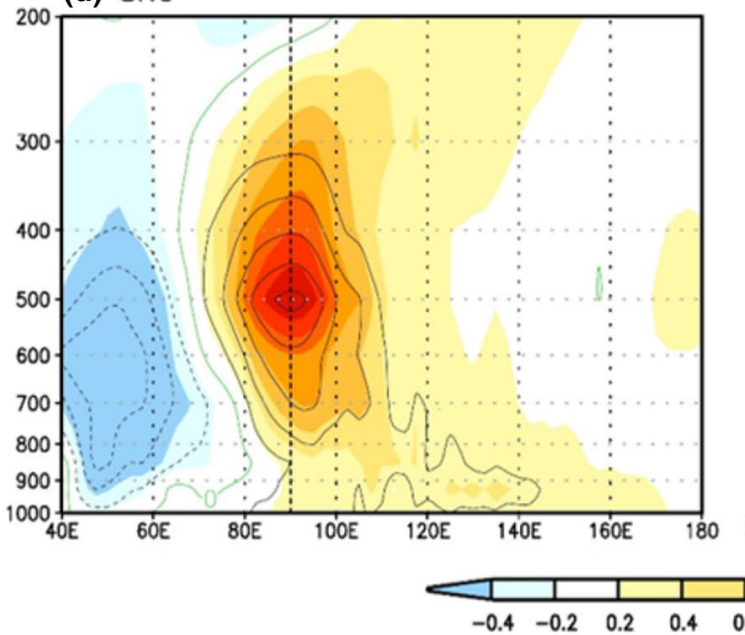

(c) $1 \mathrm{NH}$

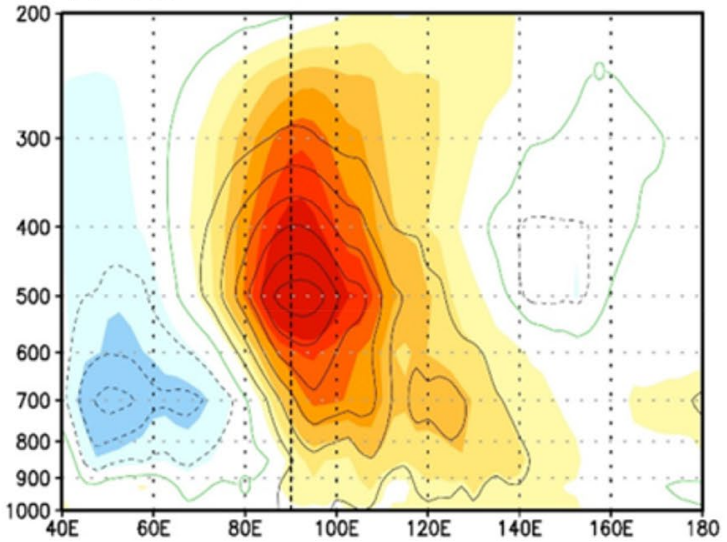

(e) $M-T D K$

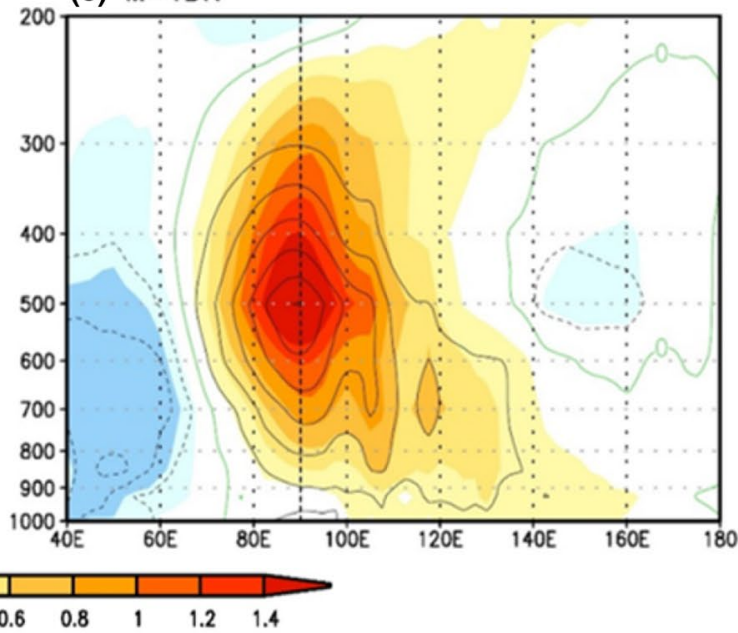

Fig. 10 The same as in Fig. 4 except for equivalent potential temperature (EPT) (K, shading) and specific humidity ( $\mathrm{g} \mathrm{kg}^{-1}$, black contour, CI 0.1 ). Green contour represents the regression coefficient of 0

In order to show changes in the vertical structure more clearly, time-lagged composites of EPT, diabatic heating and EAPE are presented in Fig. 13. The data used are collected from Del Genio and Chen (2015) for 1997-2006. The main difference in the data between Del Genio and Chen (2015) and Wang et al. (2016) is that the former includes only strong MJO events defined by the Wheeler-Hendon Index (2004), while the later includes relatively strong precipitation $\left(3 \mathrm{~mm} \mathrm{day}^{-1}\right)$ over the IO. In the observation, there is clear upward and forward tilt of the EPT in the lower troposphere, suggesting that pre-moistening occurs about 15 days in advance of the MJO peak convection. In the upper 


\section{(a) OBS}

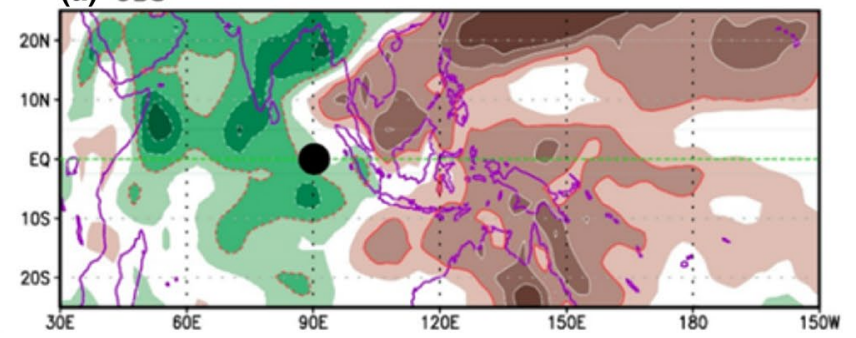

(b) CTL_TDK

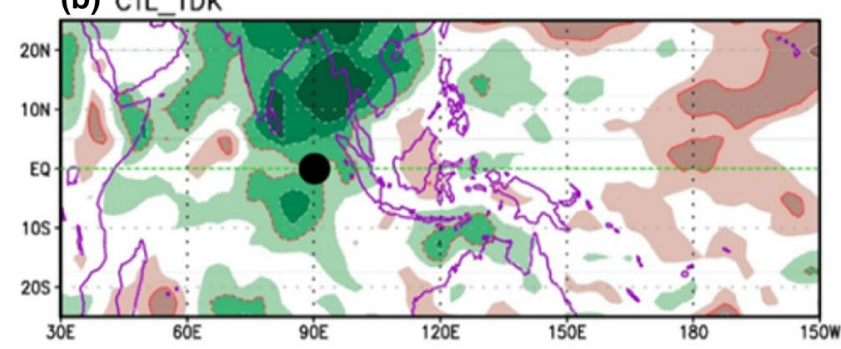

(d) SHC

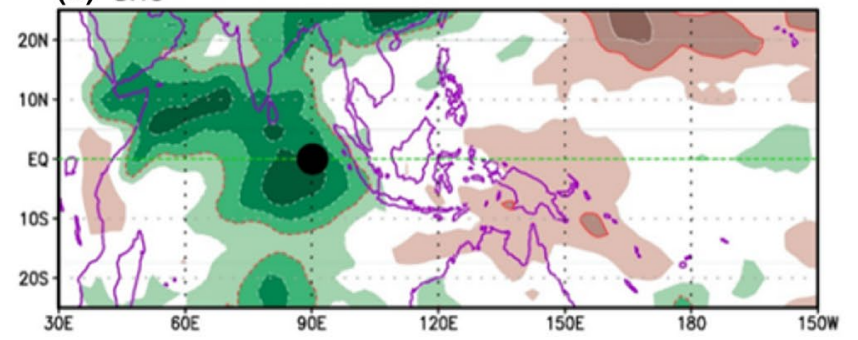

(c) $1 \mathrm{NH}$

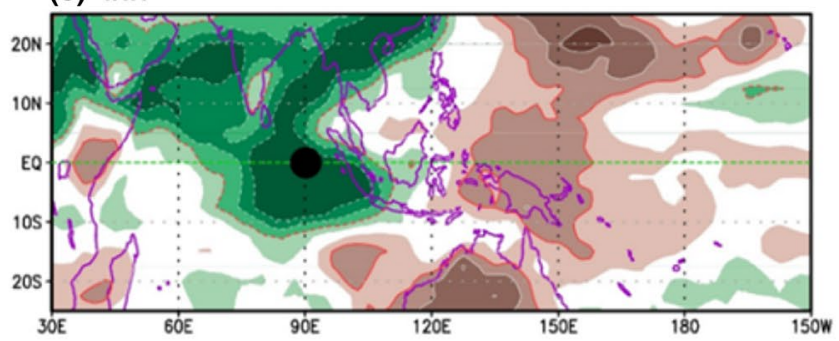

(e) $M-T D K$

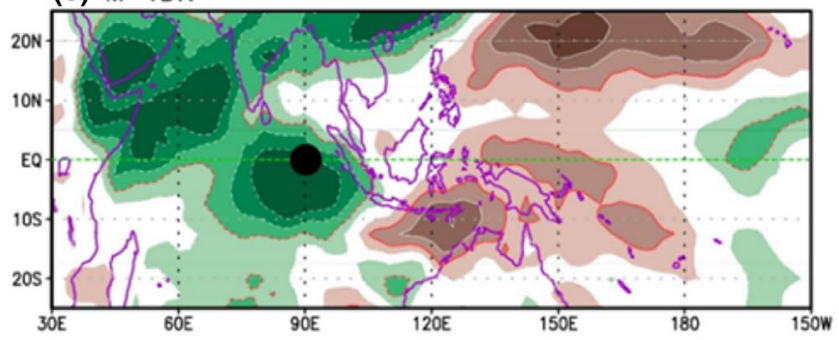

Fig. 11 The same as in Fig. 3 except for the convective instability index (K). The red contour represents the regression coefficient of \pm 0.5 . Green horizontal line is equator

troposphere, the EPT does not show tilt, which may be due to deficiency in the temperature profile. The upward and forward tilts in positive diabatic heating and EAPE anomalies are shown in Fig. 13e, h. The CTL fails to capture the observed tilts in EPT, diabatic heating and EAPE, whereas the M-TDK simulates upward tilts with large anomalies. In the M-TDK, the lower tropospheric diabatic heating, EPT and EAPE occur about 10 days before the peak MJO, which is slightly shorter than the observation. These lagged composites of EPT, diabatic heating and EAPE are consistent with the regression on the IO precipitation by Wang et al. (2018), suggesting that the EPT, diabatic heating and EAPE occur before the peak MJO in the lower troposphere and BL.

\subsection{Causes of improved MJO simulations with the modified RAS schemes}

Similar to the modified TDK schemes, the modified RAS schemes can also get better MJO propagation and more realistic structures. Figure 14 compares the MJO horizontal structures simulated in the CTL-RAS and M-RAS. In the CTL-RAS simulation, the $700 \mathrm{hPa}$ heating is very weak to the east of MJO major precipitation (Fig. 14a); the corresponding easterly wind is also weak (Fig. 14c), while the maximum westerly speed is about twice as large as the maximum easterly speed. These features are quite different from observations and the resulting $\mathrm{MJO}$ propagation is poor (Fig. 1f). In the M-RAS experiment, on the other hand, the $700 \mathrm{hPa}$ diabatic heating extends eastward from the MJO center to the Maritime Continent (Fig. 14b), resembling the observed counterpart (Fig. 6a). The heating over the Maritime Continent enhances the Kelvin wave easterly anomaly in situ and over the western Pacific (Fig. 14d). The ratio of maximum westerly to maximum easterly speed is about 1.0 , which is closer to the observation. In addition, in the M-RAS experiment, the maximum BLMC extends eastward from the MJO precipitation center to $\sim 160^{\circ} \mathrm{E}$ (Fig. 14f), while in the CTL-RAS the BLMC over the Maritime Continent is very weak (Fig. 14e). Note that in both experiments, patterns of diabatic heating are almost the same as those of the 
Fig. 12 The same as in Fig. 4 except for the MJO available potential energy (APE) generation rate $\left(\mathrm{K}^{2}\right.$ day $^{-1}$, contour $)$ and temperature anomalies $(\mathrm{K}$, shading). Green contour represents the regression coefficient of 0 . Contour starts from -100 with an interval of 200

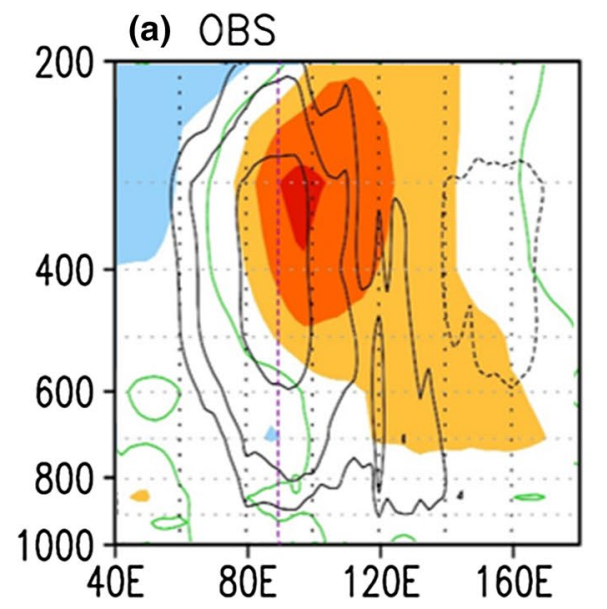

(b) CTL TDK

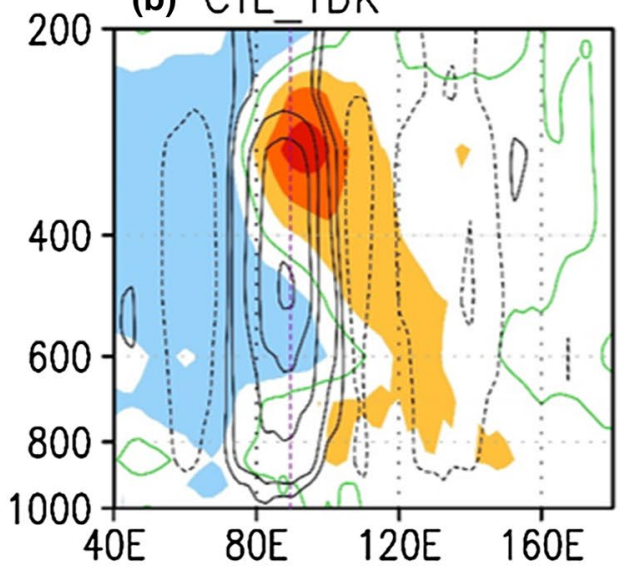

(d) $\mathrm{SHC}$

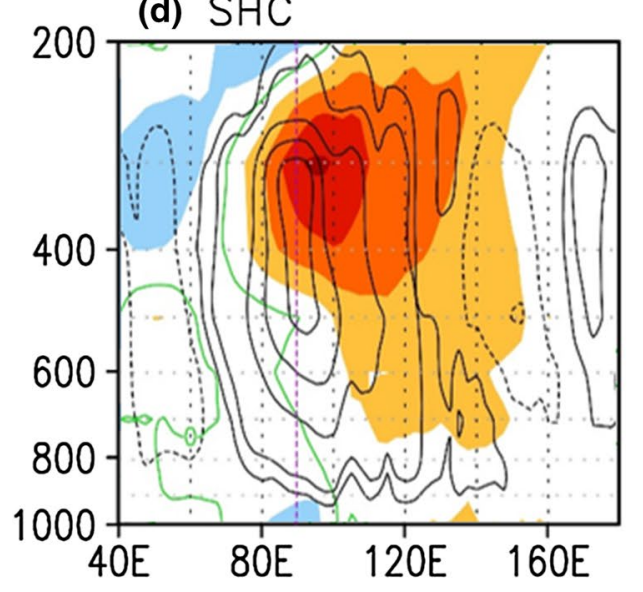

(c) $\mathrm{INH}$

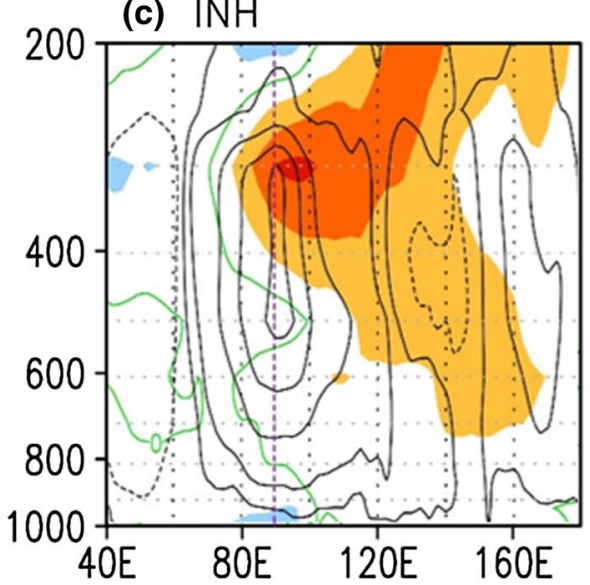

(e) $M-T D K$

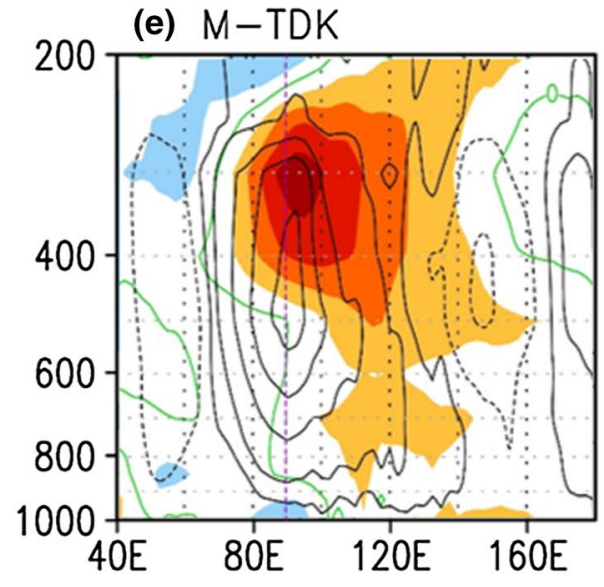

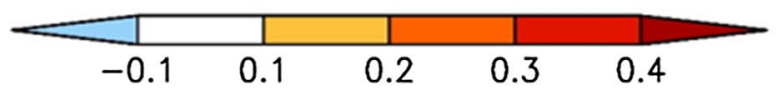

BLMC, indicating that the BLMC and diabatic heating at the lower troposphere are closely interactive. Obviously, in the CTL-RAS this interaction is weak while in the M-RAS it is considerably enhanced.

The vertical profiles of diabatic heating derived from the CTL-RAS and M-RAS simulations are also conspicuously different (Fig. 15a, b). The CTL-RAS simulates an upright heating profile, indicating that deep convection is produced directly over the EIO without gradual generation of shallow and congestus clouds ahead of the major MJO convection. In contrast, the M-RAS simulates remarkably enhanced diabatic heating in the lower troposphere to the east of the MJO 
Fig. 13 Composite of a EPT, b diabatic heating and $\mathbf{c}$ EAPE anomalies as a function of lag relative to MJO peak (a) EPT
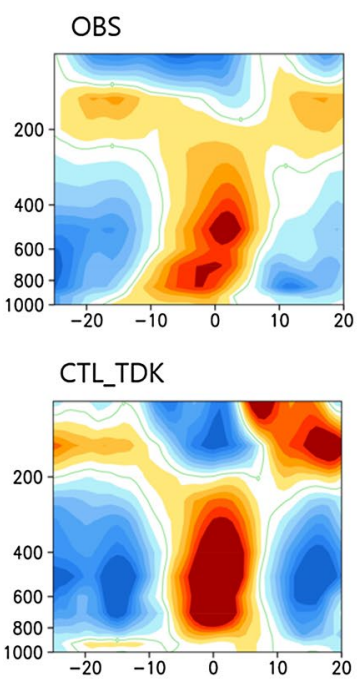

M-TDK

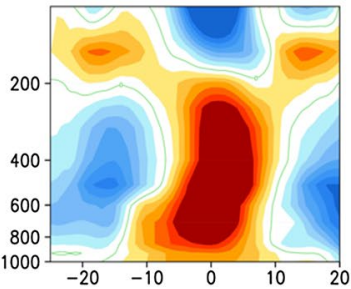

(b) Diabatic heating
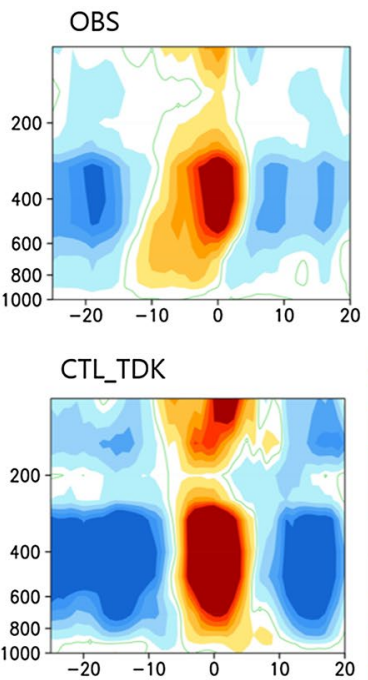

M-TDK

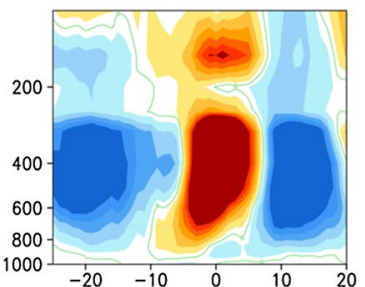

(c) EAPE
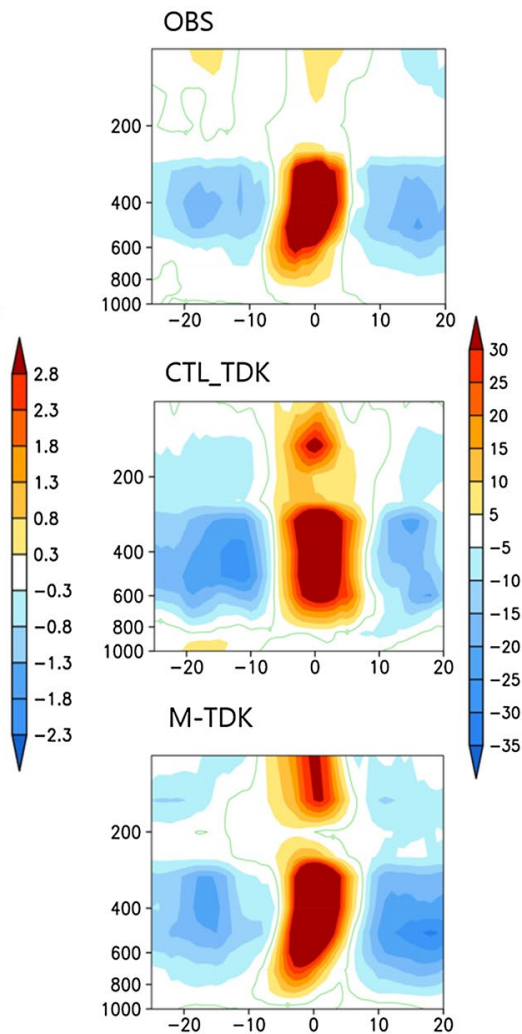

precipitation center. This vertical structure resembles that in the M-TDK run. Due to lack of the lower tropospheric heating in front of MJO propagation, the CTL-RAS does not capture the positive EAPE generation to the east of the MJO center in the lower troposphere. However, the M-RAS simulation shows the EAPE generation ahead of the MJO precipitation center, which resembles the observation (Fig. 15c, d).

\section{Conclusion and discussion}

The initially coupled version of the Nanjing University of Information Science and Technology Earth System Model (NESM3.0) reproduces realistic precipitation climatology but poor MJO. To improve MJO simulation in the NESM3.0 model, we applied trio-interaction theory as a guidance to enhance the BL convergence feedback to the lower tropospheric (shallow and congestus clouds) heating. Two modified parameterizations are implemented into the model: (a) a BL depth-dependent convective inhibition (INH), and (b) a bottom-heavy diffusivity in the shallow convective scheme (SHC). These modified parameterizations are incorporated into both the TDK and RAS convective schemes. The modifications aim to enhance the lower tropospheric heating and the upward transport of

moisture from the BL to the lower troposphere. Results of sensitivity experiments show that the modified parameterizations have significantly improved the quality of MJO simulation in terms of both the eastward propagation and the three-dimensional dynamic and thermodynamic structures of the MJO without degrading model climatology and energy balance.

The mechanisms by which the modified cumulus parameterization schemes improve MJO simulation are summarized in Fig. 16. As shown in the schematic diagram, the modified scheme with INH (BL depth-dependent convective inhibition) enhances the lower tropospheric heating to the east of the MJO major convection. When the lower tropospheric heating is increased, the induced structural change, i.e., the increased Kelvin wave easterly (lower pressure) enhances the BL moisture convergence (BLMC) to the east of the MJO center. The modified scheme with SHC (bottom-heavy diffusivity in shallow convection) reinforces the upward transport of moisture and heat from the BL to the lower troposphere, thus increasing the BLMC feedback to the shallow and congestus cloud heating and transition to deep convection. As a result, the modified schemes significantly promote the interaction between the BLMC and shallow/congestus cloud heating and enhance both the BLMC and lower tropospheric heating to the east of the MJO center. The enhanced 
(a) CTL-RAS

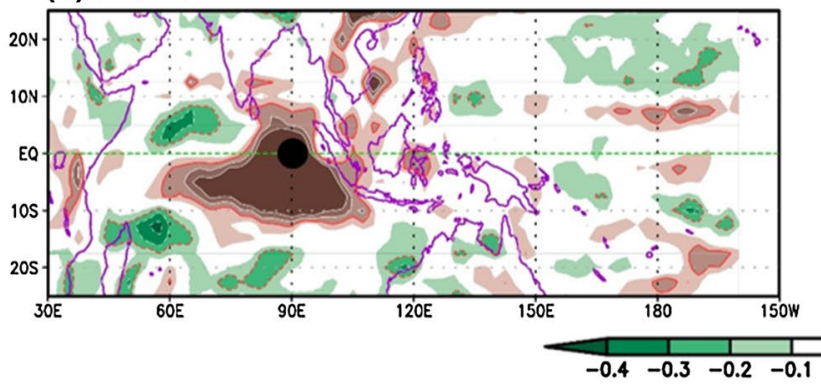

(c) CTL-RAS

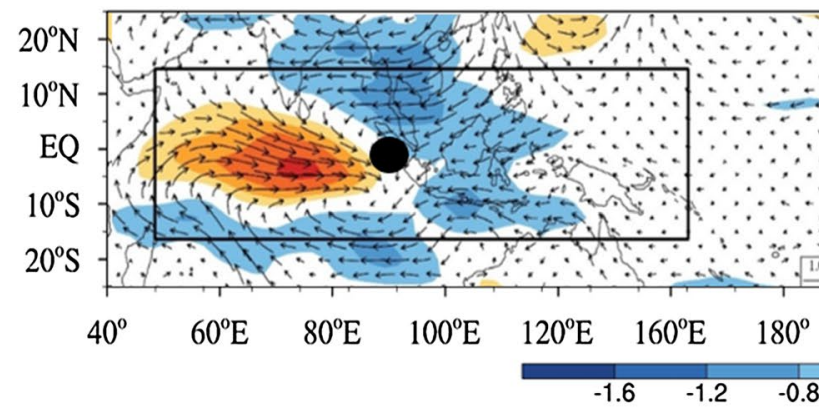

(e) CTL-RAS

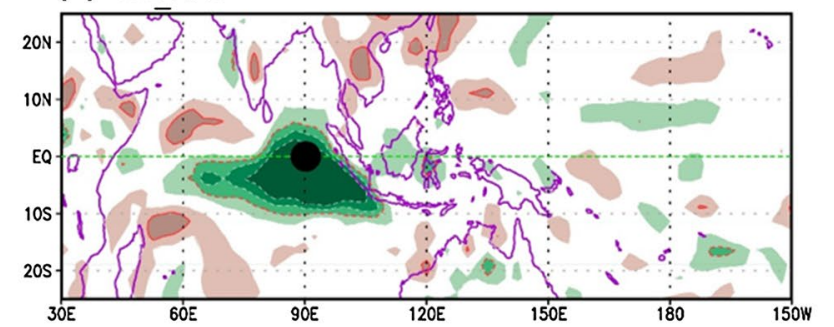

(b) M-RAS

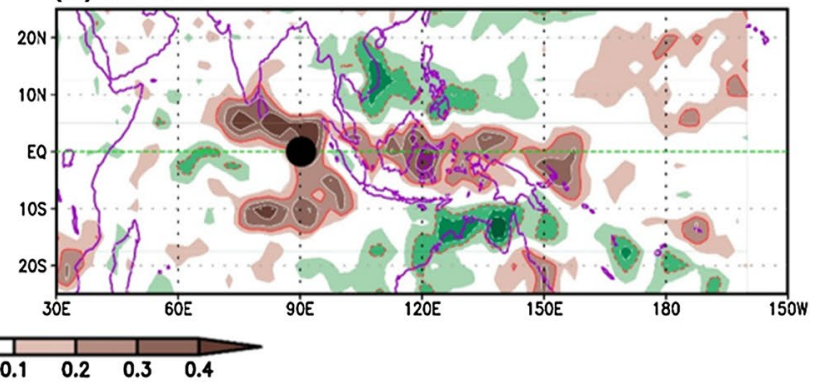

(d) M-RAS

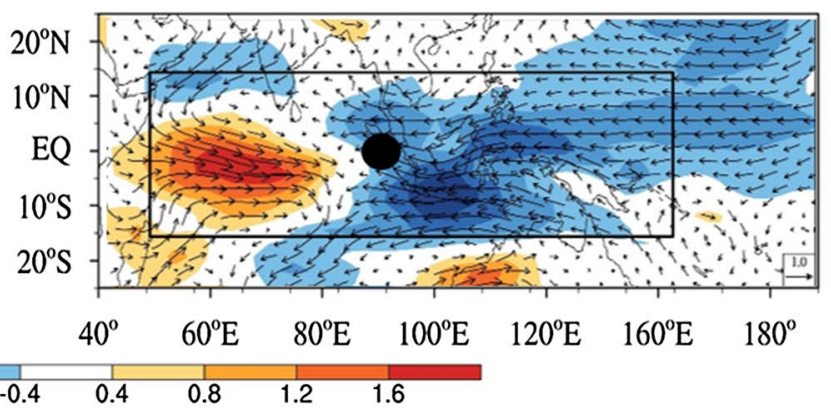

(f) M-RAS

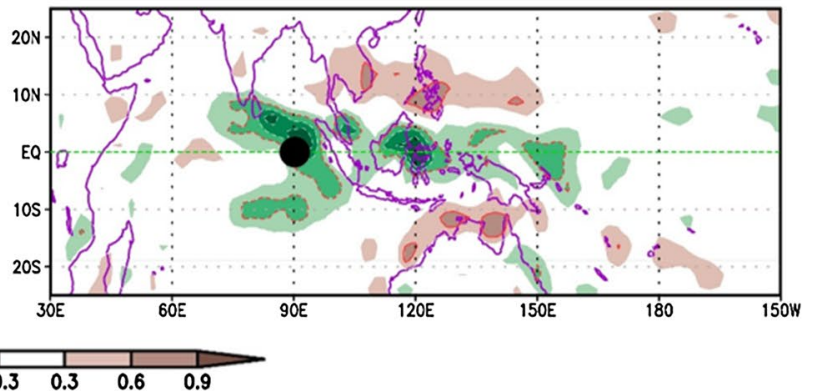

Fig. 14 Comparison of the dynamic structures simulated in the CTLRAS and M-RAS. a, b horizontal structure of diabatic heating ( $\mathrm{K}$ day $\left.^{-1}\right)$ at $700 \mathrm{hPa}$; $\mathbf{c}$, d horizontal structure of $850 \mathrm{hPa}$ wind $\left(\mathrm{m} \mathrm{s}^{-1}\right.$, vector) and $850 \mathrm{hPa}$ zonal wind speed (U850) ( $\mathrm{m} \mathrm{s}^{-1}$, shading); e, $\mathbf{f}$ horizontal structure of boundary layer moisture convergence $\left(\right.$ day $\left.^{-1}\right)$ at $925 \mathrm{hPa}$. The structures are regressed 20-70 days band pass filtered fields with reference to the MJO precipitation anomaly in the equatorial Indian Ocean $\left(10^{\circ} \mathrm{S}-10^{\circ} \mathrm{N}, 80^{\circ}-100^{\circ} \mathrm{E}\right)$, which is symbolized by the black filled circle. The regression strengths are scaled to a fixed $3 \mathrm{~mm} \mathrm{day}{ }^{-1}$ precipitation rate. The rectangular line represents the area used for PCC
BLMC favors the pre-moistening and pre-destabilization of the atmosphere to the east of the MJO center. The enhanced lower-tropospheric heating facilitates the MJO available potential energy (APE) generation to the east of the MJO center, thus promoting the MJO eastward propagation. The model improvements provide supporting evidence for the critical role of the BL moisture convergence-lower tropospheric heating interaction in MJO propagation proposed by the trio-interaction theory (Wang et al. 2016).

The modified schemes also help to replicate a more realistic MJO dynamic and thermodynamic structure. Vertical profile of the equivalent potential temperature (EPT) shows a westward and upward (rearward) tilt in the lower troposphere, reflecting the fact that the modified schemes can simulate the observed gradual deepening of the moist layer from the ground and the gradual increase of convective instability ahead of the MJO precipitation center. Vertical profile of diabatic heating also presents a clear rearward tilt in the lower troposphere, indicating that the modified schemes reproduce better multi-cloud structure of the MJO and better gradual transition from shallow to deep convective clouds. The enhanced diabatic heating increases the easterly wind anomaly to the east of MJO major convection, thereby improving the coupled Kelvin-Rossby wave structure of the MJO. The ratio of maximum Rossby wave westerly to maximum Kelvin wave easterly is reduced from 2.0 in the CTL 
Fig. 15 Comparison of the vertical structures along the equator averaged between $5^{\circ} \mathrm{S}$ and $5^{\circ} \mathrm{N}$ that are simulated in the CTL-RAS and M-RAS. a, b Diabatic heating $\left(\mathrm{K} \mathrm{day}^{-1}\right.$, shading) and anomalous Walker cell $\left(\mathrm{m} \mathrm{s}^{-1}\right.$ for zonal wind and $0.01 \mathrm{~Pa} \mathrm{~s}^{-1}$ for vertical velocity, vector). c, d Eddy available potential energy (EAPE) generation rate $\left(\mathrm{K}^{2} \mathrm{day}^{-1}\right.$, contour $)$ and temperature anomalies $(\mathrm{K}$, shading). The structures are regressed 20-70 days band pass filtered fields with reference to the precipitation anomaly in the equatorial Indian Ocean $\left(10^{\circ} \mathrm{S}-10^{\circ} \mathrm{N}, 80^{\circ}-100^{\circ} \mathrm{E}\right)$.

The regression strengths are scaled to a fixed $3 \mathrm{~mm}$ day $^{-1}$ precipitation rate and averaged over $5^{\circ} \mathrm{S}-5^{\circ} \mathrm{N}$. The intervals of contour in $\mathbf{c}, \mathbf{d}$ are same as those of shading. Green contour represents the regression coefficient of 0 . Contour starts from -100 with an interval of 200

Fig. 16 Schematic diagram illustrating the mechanisms by which the modified cumulus parameterization schemes affect MJO structures and improve the MJO eastward propagation (a) CTL-RAS

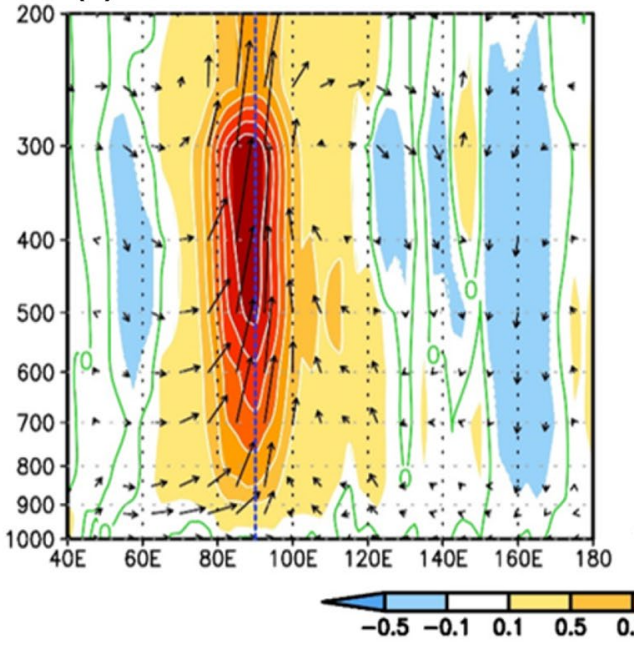

(c) CTL-RAS

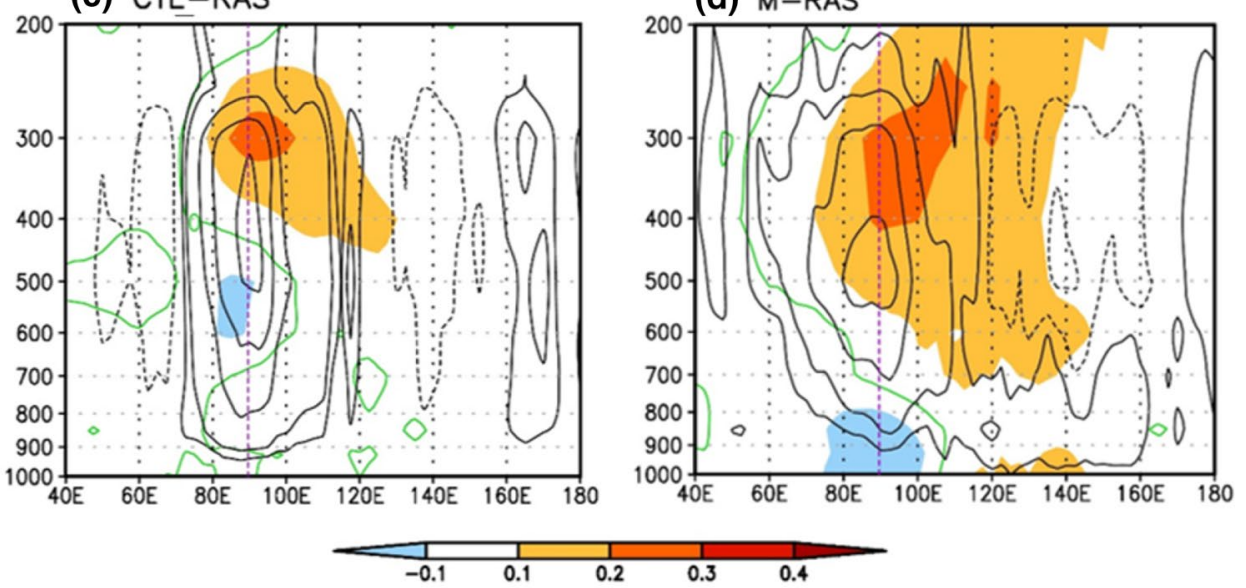

(b) M-RAS

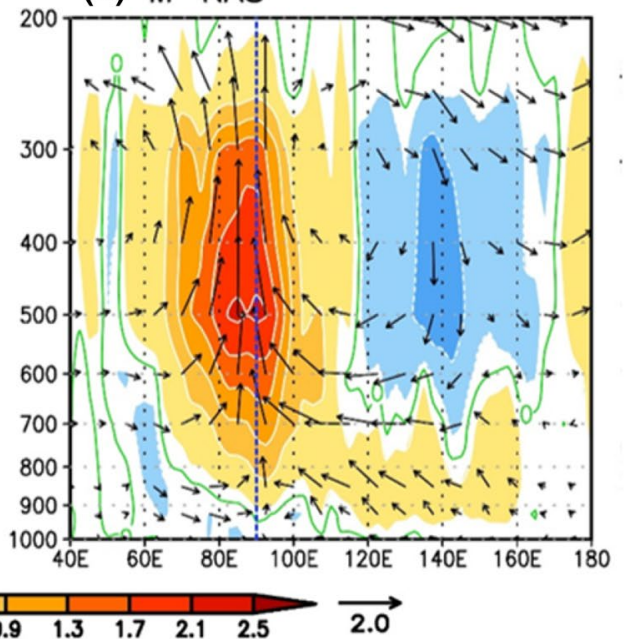

(d) M-RAS

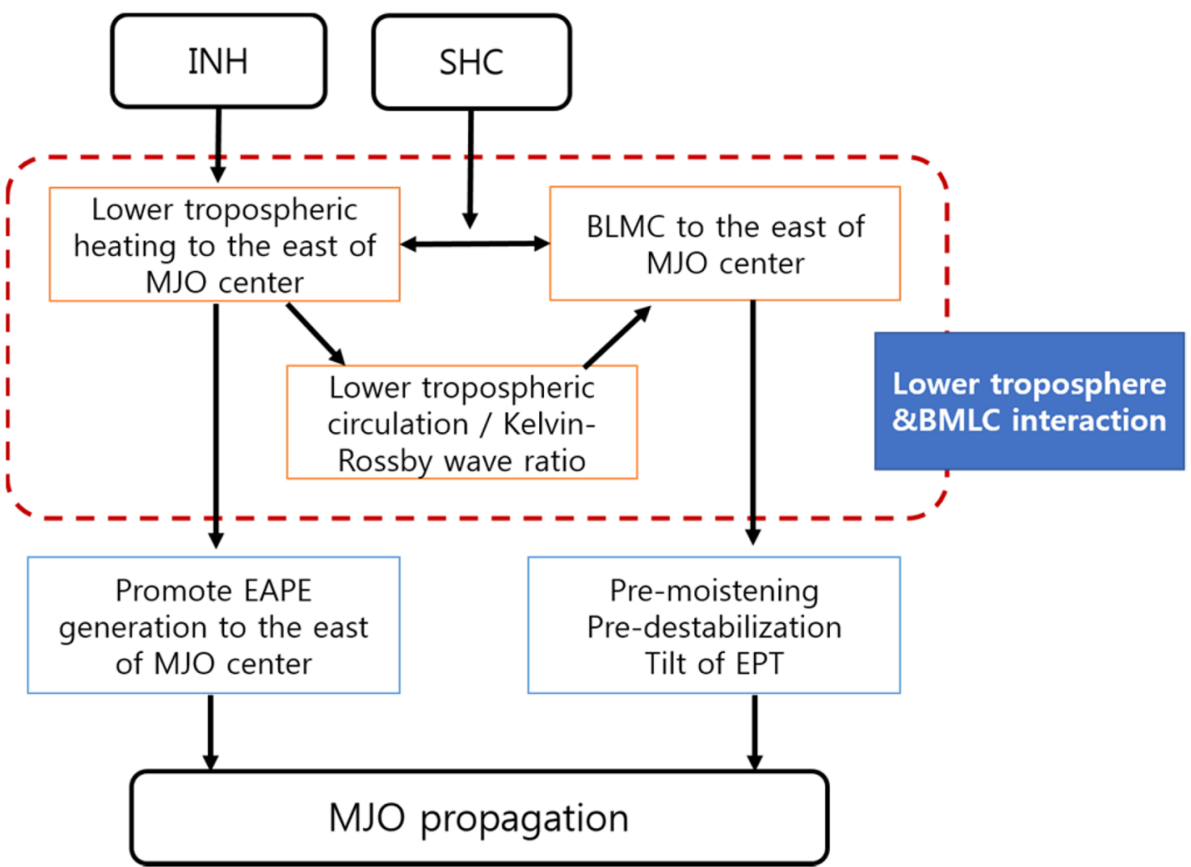


(without modification) runs to 1.0 in the modified scheme runs. The latter is much closer to the observation.

To examine whether the modified parameterizations work in another convective scheme, we implemented the modified parameterization in the RAS scheme. The RAS with the modified parameterizations (M-RAS) significantly improves the MJO eastward propagation than the RAS without the modified parameterizations. The M-RAS well represents the eastward extension of the EPT, diabatic heating, the EAPE and the coupled Rossby-Kelvin wave at lower troposphere, suggesting that the modified parameterizations may work in other convective parameterizations. However, the M-RAS tends to degrade the model climatology more than the M-TDK scheme. It also produces colder SST and smaller radiative fluxes at the TOA compared to the M-TDK, which deviates from observation. For better MJO simulation without degrading model climatology, the M-TDK would be more appropriate in the NUIST3.

It is noted that the modified parameterizations produce eastward extension of the EPT in the upper troposphere above $400 \mathrm{hPa}$. This is mainly attributed to the positive temperature anomaly to the east of the major convection center because the moisture contribution is minimal in the upper troposphere. The upper tropospheric anomalous temperature also contributes to the MJO APE generation (Wang et al. 2018). The reason for the eastward extension of the temperature anomaly may be net radiative heating (Del Genio and Chen 2015; Johnson et al. 2015). Diagnosis of the model results indicates that the warming of the upper troposphere to the east of the precipitation center is mainly attributed to longwave radiative heating caused by change of cloud cover in the upper troposphere. However, it is unclear how the cloud cover is changed in the upper troposphere because the modified parameterization is designed to enhance diabatic heating in the lower troposphere. This issue calls for further studies.

The eastward propagation speed in the model with the modified TDK scheme $\left(\sim 4 \mathrm{~m} \mathrm{~s}^{-1}\right)$ is slightly slower than that in observation $\left(\sim 4-5 \mathrm{~m} \mathrm{~s}^{-1}\right)$. At this moment, it remains unclear what causes the slower propagation speed. It may be affected by the excessive precipitation amount (Kang et al. 2013) and the associated BLMC to the east of MJO deep convection (Wang and Chen 2017). This issue will be investigated in future studies. It is noteworthy that the eastward propagation speed of the modified RAS scheme is slightly faster $\left(4.5 \mathrm{~m} \mathrm{~s}^{-1}\right)$ than that in the M-TDK, which may be due to the fact that the precipitation amount in the M-RAS is smaller than in the M-TDK (not shown), since Wang and Chen (2017) and Yang and Wang (2018) showed that the speed is related to precipitation amount in the theoretical model frame. This issue deserves further research.
Acknowledgements This work is supported by National Natural Science Foundation of China (Grant no. 41420104002) and the National Key Research and Development Program of China (Grant no. 2016YFA0600401) as well as the National Science Foundation (Climate Dynamics Division) Award no. AGS-1540783 and the NOAA/ CVP \#NA15OAR4310177. This is Publication no. XXXX of the SOEST, Publication no. YYYY of IPRC, and Publication no. ZZ of the Earth System Modeling Center (ESMC).

Open Access This article is distributed under the terms of the Creative Commons Attribution 4.0 International License (http://creativeco mmons.org/licenses/by/4.0/), which permits unrestricted use, distribution, and reproduction in any medium, provided you give appropriate credit to the original author(s) and the source, provide a link to the Creative Commons license, and indicate if changes were made.

\section{References}

Adler RF et al (2003) The version-2 global precipitation climatology project (GPCP) monthly precipitation analysis (1979-present). J Hydrometeorol 4(6):1147-1167

Andersen JA, Kuang Z (2012) Moist static energy budget of MJO-like disturbances in the atmosphere of a zonally symmetric aquaplanet. J Clim 25(8):2782-2804

Benedict JJ, Randall DA (2007) Observed characteristics of the MJO relative to maximum rainfall. J Atmos Sci 64(7):2332-2354

Benedict JJ et al (2014) Gross moist stability and MJO simulation skill in three full-physics GCMs. J Atmos Sci 71(9):3327-3349

Bladé I, Hartmann DL (1993) Tropical intraseasonal oscillations in a simple nonlinear model. J Atmos Sci 50(17):2922-2939

Bony S, Emanuel KA (2005) On the role of moist processes in tropical intraseasonal variability: Cloud-radiation and moisture-convection feedbacks. J Atmos Sci 62(8):2770-2789

Cai Q et al (2013) Impacts of shallow convection on MJO simulation: a moist static energy and moisture budget analysis. J Clim 26(8):2417-2431

Cao J et al (2018) The NUIST Earth System Model (NESM) version 3: description and preliminary evaluation. Geosci Model Dev 11:2975-2993

Dee DP et al (2011) The ERA-Interim reanalysis: configuration and performance of the data assimilation system. Q J R Meteorol Soc 137(656):553-597

Del Genio AD, Chen Y (2015) Cloud-radiative driving of the MaddenJulian Oscillation as seen by the A-train. J Geophys Res Atmos 120(11):5344-5356

Fu X, Wang B (2009) Critical roles of the stratiform rainfall in sustaining the Madden-Julian Oscillation: GCM experiments. J Clim 22(14):3939-3959

Giorgetta MA et al (2013) The atmospheric general circulation model ECHAM6: model description, tech. rep. Max Planck Institute for Meteorology, Hamburg

Grabowski WW, Moncrieff M (2004) Moisture-convection feedback in the tropics. Q J R Meteorol Soc 130(604):3081-3104

Hendon HH, Salby ML (1994) The life cycle of the Madden-Julian Oscillation. J Atmos Sci 51(15):2225-2237

Holloway CE et al (2013) The effects of explicit versus parameterized convection on the MJO in a large-domain high-resolution tropical case study. Part I: characterization of large-scale organization and propagation. J Atmos Sci 70(5):1342-1369

Hsu P-c, Li T (2012) Role of the boundary layer moisture asymmetry in causing the eastward propagation of the Madden-Julian Oscillation. J Clim 25(14):4914-4931 
Iacono MJ et al (2008) Radiative forcing by long-lived greenhouse gases: calculations with the AER radiative transfer models. J Geophys Res Atmos 113:D13

Jiang X et al (2015) Vertical structure and physical processes of the Madden-Julian Oscillation: exploring key model physics in climate simulations. J Geophys Res Atmos 120(10):4718-4748

Johnson RH et al (1999) Trimodal characteristics of tropical convection. J Clim 12(8):2397-2418

Johnson RH et al (2015) Sounding-based thermodynamic budgets for DYNAMO. J Atmos Sci 72(2):598-622

Kang I-S et al (2013) The role of SST structure in convectively coupled Kelvin-Rossby waves and its implications for MJO formation. J Clim 26(16):5915-5930

Katsumata $\mathrm{M}$ et al (2009) Observed synoptic-scale variability during the developing phase of an ISO over the Indian Ocean during MISMO. J Atmos Sci 66(11):3434-3448

Kemball-Cook SR, Weare BC (2001) The onset of convection in the Madden-Julian Oscillation. J Clim 14(5):780-793

Khouider B, Majda AJ (2006) Model multi-cloud parameterizations for convectively coupled waves: detailed nonlinear wave evolution. Dyn Atmos Oceans 42(1):59-80

Kikuchi K, Takayabu YN (2004) The development of organized convection associated with the MJO during TOGA COARE IOP: trimodal characteristics. Geophys Res Lett 31(10):L10101

Kikuchi K et al (2012) Bimodal representation of the tropical intraseasonal oscillation. Clim Dyn 38(9-10):1989-2000

Kim D et al (2011) A systematic relationship between intraseasonal variability and mean state bias in AGCM simulations. J Clim 24(21):5506-5520

Kim D et al (2014) Process-oriented MJO simulation diagnostic: moisture sensitivity of simulated convection. J Clim 27(14):5379-5395

Kuang Z (2008) A moisture-stratiform instability for convectively coupled waves. J Atmos Sci 65(3):834-854

Lee MI et al (2001) Influence of cloud-radiation interaction on simulating tropical intraseasonal oscillation with an atmospheric general circulation model. J Geophys Res Atmos 106(D13):14219-14233

Li $\mathrm{S}$ et al (2018) Estimating convection parameters in the GFDL CM2. 1 model using ensemble data assimilation. J Adv Model Earth Syst 10(4):989-1010

Lin J-L, Mapes BE (2004) Radiation budget of the tropical intraseasonal oscillation. J Atmos Sci 61(16):2050-2062

Lin J et al (2004) Stratiform precipitation, vertical heating profiles, and the Madden-Julian Oscillation. J Atmos Sci 61(3):296-309

Lin J-L et al (2008) The impacts of convective parameterization and moisture triggering on AGCM-simulated convectively coupled equatorial waves. J Clim 21(5):883-909

Lott F (1999) Alleviation of stationary biases in a GCM through a mountain drag parameterization scheme and a simple representation of mountain lift forces. Mon Weather Rev 127(5):788-801

Madden RA, Julian PR (1972) Description of global-scale circulation cells in the tropics with a $40-50$ days period. J Atmos Sci 29(6):1109-1123

Maloney ED (2009) The moist static energy budget of a composite tropical intraseasonal oscillation in a climate model. J Clim 22(3):711-729

Maloney ED, Hartmann DL (1998) Frictional moisture convergence in a composite life cycle of the Madden-Julian Oscillation. J Clim 11(9):2387-2403

Maloney ED et al (2010) Intraseasonal variability in an aquaplanet general circulation model. J Adv Model Earth Syst 2:1-24. https ://doi.org/10.3894/JAMES.2010.2.5

Mapes BE (2000) Convective inhibition, subgrid-scale triggering energy, and stratiform instability in a toy tropical wave model. J Atmos Sci 57(10):1515-1535
Möbis B, Stevens B (2012) Factors controlling the position of the intertropical convergence zone on an aquaplanet. J Adv Model Earth Syst 4(4):M00A04

Nordeng TE (1994) Extended versions of the convective parameterization scheme at ECMWF and their impact on the mean and transient activity of the model in the tropics. ECMWF Res Dep Tech Memo. 41

Peters K et al (2017) Improved MJO-simulation in ECHAM6. 3 by coupling a stochastic multicloud model to the convection scheme. J Adv Model Earth Syst 9(1):193-219

Pritchard MS, Bretherton CS (2014) Causal evidence that rotational moisture advection is critical to the superparameterized MaddenJulian Oscillation. J Atmos Sci 71(2):800-815

Raddatz T et al (2007) Will the tropical land biosphere dominate the climate-carbon cycle feedback during the twenty-first century? Clim Dyn 29(6):565-574

Raymond DJ (2001) A new model of the Madden-Julian Oscillation. J Atmos Sci 58(18):2807-2819

Seo K-H, Wang W (2010) The Madden-Julian Oscillation simulated in the NCEP climate forecast system model: the importance of stratiform heating. J Clim 23(18):4770-4793

Shi L et al (2009) The role of stochastic forcing in ensemble forecasts of the 1997/98 El Nino. J Clim 22(10):2526-2540

Sobel A, Maloney E (2012) An idealized semi-empirical framework for modeling the Madden-Julian Oscillation. J Atmos Sci 69(5):1691-1705

Sobel A, Maloney E (2013) Moisture modes and the eastward propagation of the MJO. J Atmos Sci 70(1):187-192

Stevens B et al (2013) Atmospheric component of the MPI-M earth system model: ECHAM6. J Adv Model Earth Syst 5(2):146-172

Thayer-Calder K, Randall DA (2009) The role of convective moistening in the Madden-Julian Oscillation. J Atmos Sci 66(11):3297-3312

Tian B et al (2006) Vertical moist thermodynamic structure and spatial-temporal evolution of the MJO in AIRS observations. J Atmos Sci 63(10):2462-2485

Tiedtke M (1989) A comprehensive mass flux scheme for cumulus parameterization in large-scale models. Mon Weather Rev 117(8):1779-1800

Tiedtke $\mathrm{M}$ et al (1988) Tropical forecasting at ECMWF: The influence of physical parametrization on the mean structure of forecasts and analyses. Q J R Meteorol Soc 114(481):639-664

Tokioka T et al (1988) The equatorial 30-60 days oscillation and the Arakawa-Schubert penetrative cumulus parameterization. J Meteorol Soc Jpn Ser II 66(6):883-901

Tseng K-C et al (2015) Moistening processes for Madden-Julian Oscillations during DYNAMO/CINDY. J Clim 28(8):3041-3057

Valcke $\mathrm{S}$ et al (2013) OASIS3-MCT user guide, OASIS3-MCT 2.0. CERFACS/CNRS SUC URA(1875)

Virts KS, Wallace JM (2010) Annual, interannual, and intraseasonal variability of tropical tropopause transition layer cirrus. J Atmos Sci 67(10):3097-3112

Vitart F (2014) Evolution of ECMWF sub-seasonal forecast skill scores. Q J R Meteorol Soc 140(683):1889-1899

Vitart F, Molteni F (2010) Simulation of the Madden-Julian Oscillation and its teleconnections in the ECMWF forecast system. Q J R Meteorol Soc 136(649):842-855

Waliser DE (2006) Intraseasonal variability. The Asian monsoon. Springer, Berlin, pp 203-257

Waliser D et al (2006) The experimental MJO prediction project. Bull Am Meteorol Soc 87(4):425-431

Waliser D et al (2009) MJO simulation diagnostics. J Clim 22 (11): 3006-3030

Wang B (1988) Dynamics of tropical low-frequency waves: an analysis of the moist Kelvin wave. J Atmos Sci 45(14):2051-2065 
Wang B, Chen G (2017) A general theoretical framework for understanding essential dynamics of Madden-Julian Oscillation. Clim Dyn 49(7-8):2309-2328

Wang B, Lee S-S (2017) MJO propagation shaped by zonal asymmetric structures: results from 24 GCM simulations. J Clim 30(19):7933-7952

Wang B, Li T (1994) Convective interaction with boundary-layer dynamics in the development of a tropical intraseasonal system. J Atmos Sci 51(11):1386-1400

Wang B, Rui H (1990) Dynamics of the coupled moist Kelvin-Rossby wave on an equatorial $\beta$-plane. J Atmos Sci 47(4):397-413
Wang B et al (2016) A trio-interaction theory for Madden-Julian Oscillation. Geosci Lett 3(1):34

Wang B et al (2018) Dynamics-oriented diagnostics for the MaddenJulian Oscillation. J Clim 31(8):3117-3135

Woolnough SJ et al (2001) The organization of tropical convection by intraseasonal sea surface temperature anomalies. Q J R Meteorol Soc 127(573):887-907

Yanai M et al (1973) Determination of bulk properties of tropical cloud clusters from large-scale heat and moisture budgets. J Atmos Sci 30(4):611-627 